THE INFLUENCE OF VALIDATION ON ACADEMIC OUTCOMES FOR OCEANIA COMMUNITY COLLEGE STUDENTS

\author{
AS \\ 35 \\ 2018 \\ EDD \\ - 453 \\ A dissertation submitted to the faculty of \\ San Francisco State University \\ In partial fulfillment of \\ The Requirements for \\ The Degree \\ Doctor of Education \\ In \\ Educational Leadership
}

by

Ronald J. Andrade

San Francisco, California

August 2018 
Copyright by

Ronald J. Andrade

2018 


\section{CERTIFICATION OF APPROVAL}

I certify that I have read The Influence of Validation on Academic Outcomes for Oceania Community College Students by Ronald J. Andrade, and that in my opinion this work meets the criteria for approving a dissertation submitted in partial fulfillment of the requirements for the degree: Doctor of Education in Educational Leadership at San Francisco State University.

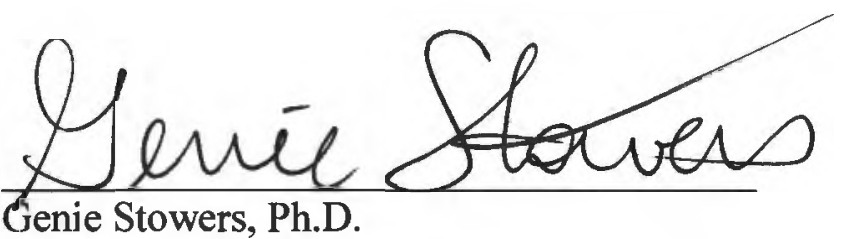

Professor, Public Administration

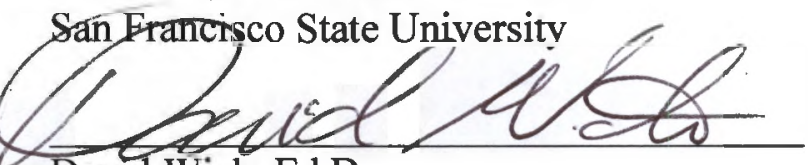

David Wick, Ed.D.

Professor, IEMP

Middlebury Institute of International Studies at Monterey

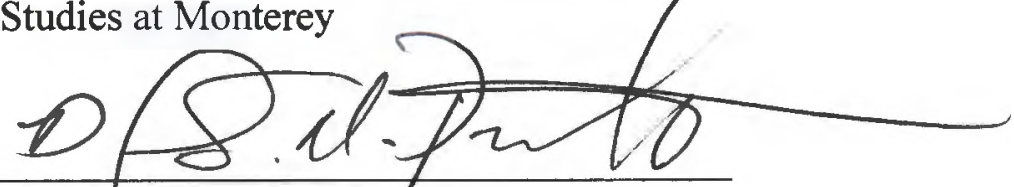

David Ga'oupu Palaita.fPh.D.

Professor, Interdisciplinary Studies

City College of San Francisco 


\title{
THE INFLUENCE OF VALIDATION ON ACADEMIC OUTCOMES FOR OCEANIA COMMUNITY COLLEGE STUDENTS
}

\author{
Ronald J. Andrade \\ San Francisco State University \\ 2018
}

The purpose of this study was to examine the influence of validation experiences on academic outcomes for Oceania community college students, utilizing Rendón's theory of validation. Quantitative analysis of survey data showed Oceania students at a midsized community college were experiencing validating interactions with faculty and staff. The relationship identified between validation and students' sense of integration/competent membership appears to be influenced by participation in a culturally sustaining learning community. Findings further suggest that participation in the learning community influenced students' grades as well as their continued enrollment in college.

Implications of the research include: creating and maintaining a validating environment for Oceania students through professional enhancements for faculty and staff in areas of cultural competency and initiating validating interaction with students; using the Oceania learning community as a model for other institutions to support student success; the need for additional research using qualitative methods to include more Oceania student voices, exploring elements of learning communities that are most supportive of students; and examining reasons for early departure of Oceania students.

I certify that the Abstract is a correct representation of the content of this dissertation. 

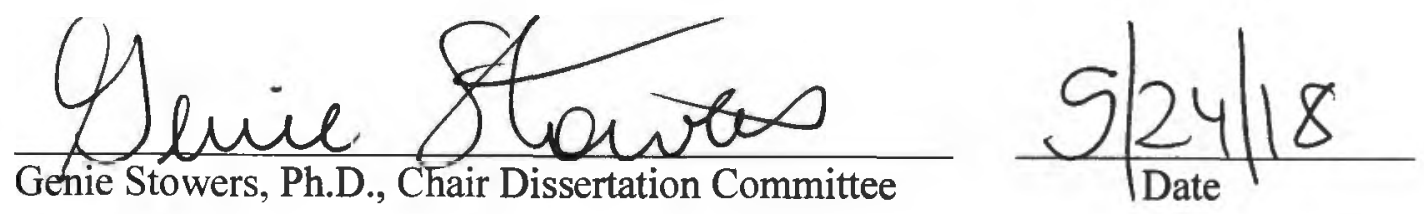


\section{ACKNOWLEDGEMENTS}

Undertaking a doctoral program has been a considerable effort which I would not have been able to accomplish without the support, guidance, friendship, and love of so many people. I want to offer a special thanks to my wife Melissa for her understanding well beyond what any wedding vows may have implied. Also, to Genie, David and Vika for their encouragement and belief in my educational journey. A heartfelt shout out to TG for their input and critical eye that made my thinking and writing so much clearer. To family and friends for the many missed events and time not spent together, I cannot hope to repay that lost time but I will try to make up. Finally, I owe a debt of gratitude to Oceania for inviting me to study with you so that we may all learn together. WE are ocean. 


\section{TABLE OF CONTENTS}

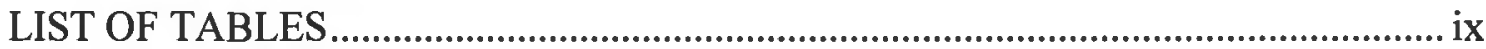

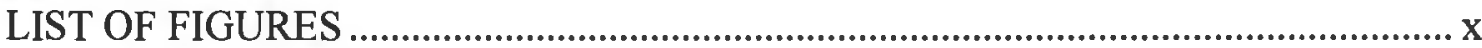

LIST OF APPENDICES......................................................................................

Chapter One: Introduction and Statement of Problem ....................................................... 1

Context and Background of the Problem........................................................................ 5

Purpose of the Study ...................................................................................................... 12

Research Questions................................................................................................. 13

Definitions of Key Terms ........................................................................................... 14

Assumptions and Limitations .............................................................................. 15

Summary and Organization of Dissertation ........................................................ 17

Chapter Two: Review of Relevant Literature.................................................................. 19

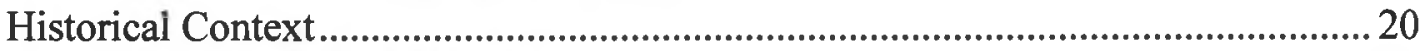

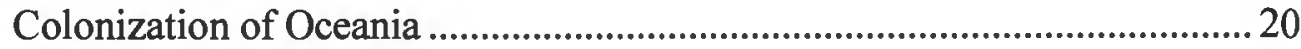

The Role of Diaspora............................................................................................. 23

Mis-aggregating Oceania Students in the American Education System ...................22

Model Minority Myth and Failure to Disaggregate......................................... 28

Academic Achievement Factors ...................................................................................... 31

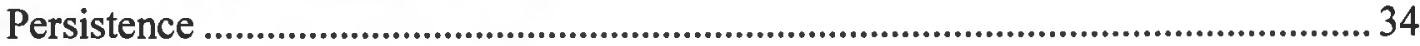

The Impact of Learning Communities............................................................ 40

Validation .................................................................................................................. 41

Summary and Implications ....................................................................................... 51

Chapter Three: Methodology .......................................................................................... 54

Researcher Positionality .........................................................................................5 54

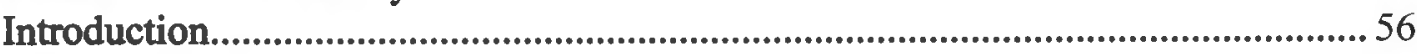

Research Design .....................................................................................................5

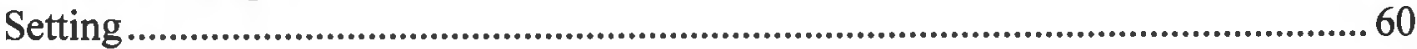

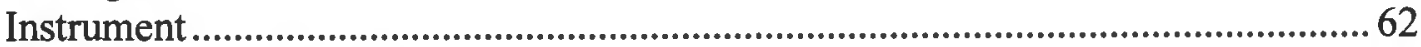

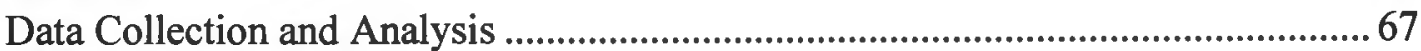

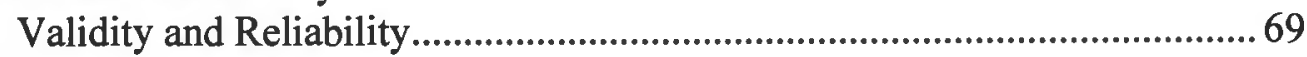

Ethical Considerations ..................................................................................... 70

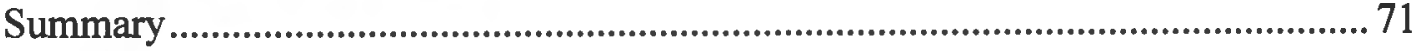

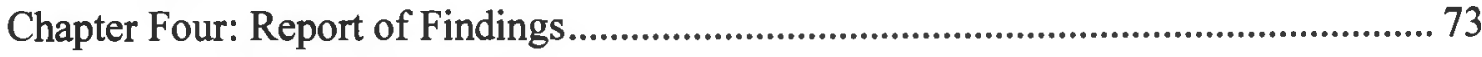




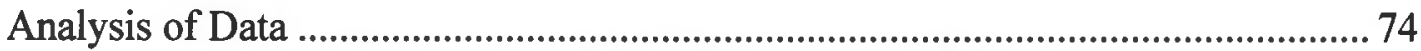

Descriptive and Frequency Data for Major Variables...................................74

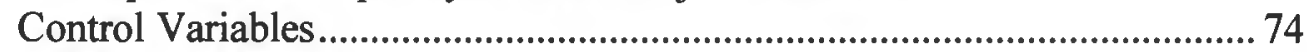

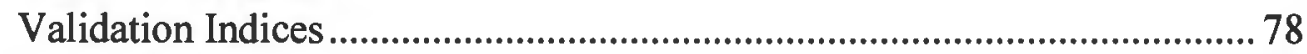

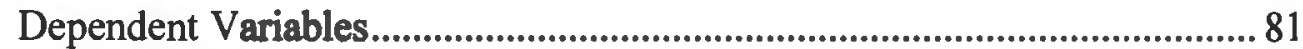

Findings related to Research Questions................................................................. 84

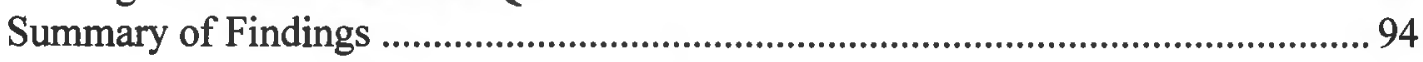

Chapter Five: Discussion and Recommendations ........................................................ 96

Interpretation and Discussion of Findings................................................................91

Implications and Recommendations for Leadership and Practice............................ 100

Developing Individual Capacity ............................................................... 101

Expanding Institutional Capacity ................................................................. 103

Curricular and Pedagogical Approaches .................................................. 104

Recommendations for Future Research............................................................. 106

Disseminating Findings ....................................................................................... 108

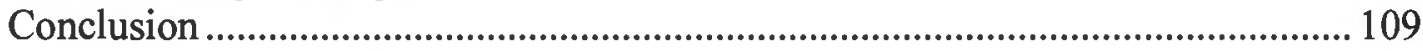

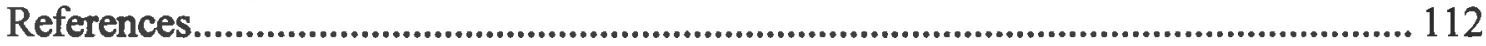

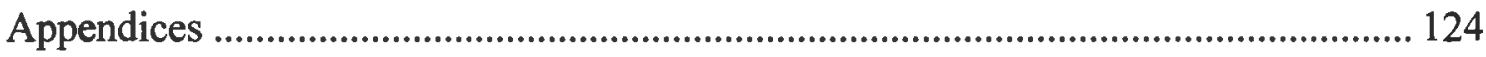




\section{LIST OF TABLES}

Table

1. National Post-Secondary Degree Attainment and Population Growth ......................... 4

2. Racial/Ethnic Identity of Students at Midsized Community College.......................... 61

3. Demographic Control Variables Collected through Survey Instrument.....................64

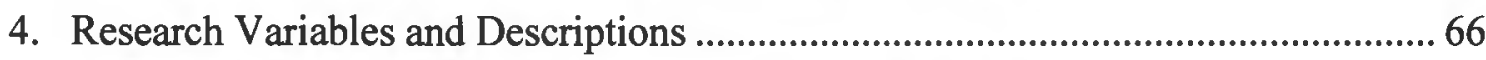

5. Demographic and Control Variables and their Operationalization ............................74

6. Age in Ranges of Respondents, All Oceania Students at Midsized Community College (MCC) and Total MCC Student Population.................................................... 77

7. Gender Identity of Respondents, All Oceania Students at MCC and Total MCC Student Population........................................................................................................ 78

8. Validation by Faculty and Validation by Others ……................................................ 79

9. Mean, Median and Standard Deviation of Interval Level Dependent Variables...... 81

10. Faculty Validation Index Descriptives ........................................................................ 84

11. Items Most Strongly Correlated with Faculty Validation Index ............................... 87

12. Validation by Others Index by Age Range ................................................................... 89

13. Validation by Others Index by Gender Identity ......................................................... 89

14. Distribution of GPA Coded for Ranges and Oceania Learning Community Participation 


\section{LIST OF FIGURES}

Figure Page

1. Tinto's Longitudinal Model of Institutional Departure ............................................... 37

2. Frequency Distribution of Faculty Validation Index..................................................8 80

3. Frequency Distribution of Validation by Others .................................................... 80

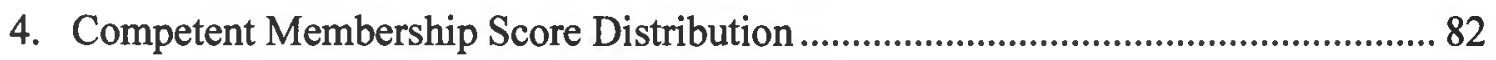

5. Cumulative Grade Point Average Distribution.......................................................... 82

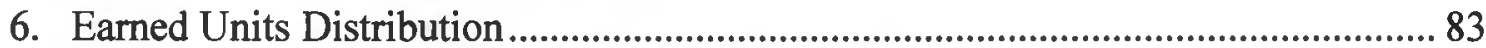

7. Mean Faculty Validation Index by Gender Identity ..................................................... 85

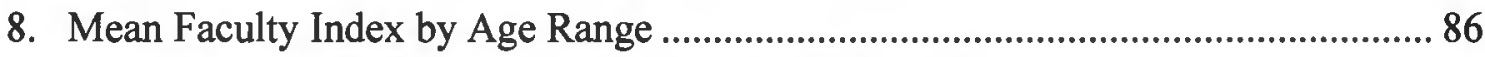

9. Frequency Distribution of Validation by Others Index ..............................................8 88

10. Scattergram with Goodness of Fit Line between Faculty Validation Index and Competent Membership................................................................................................ 91

11. Scattergram with Goodness-of-Fit Line Between Validation by Others and Competent Membership.................................................................................................... 92 


\section{LIST OF APPENDICES}

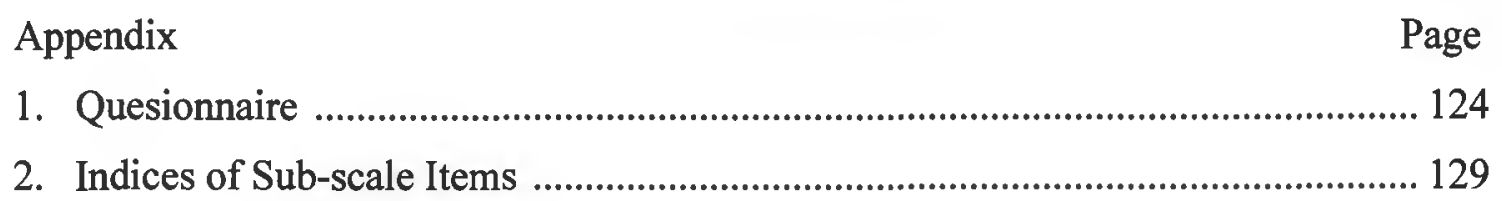


Chapter One: Introduction and Statement of Problem

Community colleges serve as the gateway to post-secondary education for many students. Nationally, community colleges enrolled $39 \%$ of all undergraduates in 2014 , and California's community college system is the largest in the nation. Encompassing 114 colleges California community colleges enrolled approximately 2.1 million students in 2017 more than half of whom are from historically underrepresented and underserved populations (California Community College Chancellor's Office, 2017). With open access and low tuition, the California community college system has several stated goals including the preparation of students to transfer to four-year universities, awarding of Associate's degrees and certificates, and workforce entry through career and technical education (California Community College Chancellor's Office, 2017). Yet, many students from historically underrepresented and underserved populations have had limited success in achieving these goals, as is evident in the disparate levels of degree attainment of different student populations (Goldrick-Rab, 2010; Moore \& Shulock, 2010). Studying the academic outcomes of different student populations and factors that contribute to their success is a major step in supporting their post-secondary educational achievement. The research conducted for this study explored perceived validation (Rendón, 1994; 2002) experiences of Oceania students, those with cultural and ethnic roots in Hawaii, Guam, Samoa, or other Pacific Islands, enrolled in a California community college, and sought to explore the impact of validating 
interactions and their relationship to students' integration, academic outcomes and persistence

Students pursue postsecondary education and career training for many reasons but the importance of college participation and completion is often framed in the context of personal and societal benefits that a more highly educated populace produces. There is a significant difference in lifetime earnings between an individual with a high school diploma and one with a four-year degree (Karen \& Dougherty, 2005; Kirsch, Braun, Yamamoto, \& Sum, 2007). The difference in lifetime earnings can be as much as $\$ 1$ million more for someone with a four-year degree (Baum, Ma \& Payea, 2013; Carnevale, Rose, \& Cheah, 2011). The individual financial benefits of higher levels of education are significant and are reflected in the value of higher tax revenues and greater general economic activity (Baum, Ma \& Payea, 2013; Engle \& Tinto, 2007; McKinsey \& Company, 2009), but there are additional individual benefits associated with higher levels of education beyond greater personal earnings.

A college education not only supports individual economic and social mobility but also promotes improved health and personal behaviors that benefit the larger society through decreased demands for social services. Higher education levels are associated with healthier lifestyles, lower rates of incarceration and greater rates of civic engagement through activities such as voting and volunteerism (Baum, Ma \& Payea, 2013). Research suggests, for example, that college graduates are more involved in their 
children's lives and early education with greater rates of preschoolers who are read to at least three times per week (Cunningham, 2006; Baum, May \& Payea, 2013). However, before the benefits of education can be reaped, students need to pass courses and persist in their goals of transfer, degree completion or professional development.

There are individual and societal benefits to a more highly educated population, additionally there is a recognized need for greater numbers of college graduates to satisfy current and future demand for a more highly educated and skilled workforce (Kirsch, Braun, Yamamoto \& Sum, 2007; Neumark, Johnson, and Mejia, 2012; Public Policy Institute of California, 2017). Projections from the Public Policy Institute of California (2018) suggest a potential shortfall of over 1 million workers with at least a bachelor's degree to meet the demands of the state's economy. With changing demographics there are growing numbers of college-age students who are from populations who have historically been underrepresented in higher education (Public Policy Institute of California, 2017). As the anticipated growth in population rates in Table 1 show, Oceania students are expected to grow at the third fastest rate, behind Asian and Hispanic populations. However, as data in Table 1 also shows, equitable rates of academic achievement are not being reached by historically underrepresented and underserved students in community colleges. The percentage of people 25 to 29 yearsold with an Associate's degree or higher show significant variation by racial/ethnic background. White and Asian students show rates of degree attainment far higher than 
those of historically underrepresented and underserved groups. It is worth noting that while this census data uses the category Native Hawaiian other Pacific Islander, throughout this study the term Oceania is used to describe those with origins in the islands of the Pacific.

Table 1

National Post-Secondary Degree Attainment and Population Growth

\begin{tabular}{lcc}
\hline \multicolumn{1}{c}{ Ethnicity } & $\begin{array}{c}\text { \% Associate's or } \\
\text { higher degree }\end{array}$ & $\begin{array}{c}\text { \% Growth in } \\
\text { Population by 2060* }\end{array}$ \\
\hline White & 54.0 & 15.5 \\
Black or African American & 31.1 & 42.0 \\
American Indian or Alaska Native & 22.3 & 41.7 \\
Asian & 71.7 & 128.1 \\
Native Hawaiian other Pacific Islander & 24.9 & 62.6 \\
Hispanic & 25.7 & 114.8 \\
\hline
\end{tabular}

^ Percentage of persons 25 to 29 years old with an associate's or higher degree

*Source: Census Bureau, Current Population Survey (CPS), Annual Social and Economic Supplement, 1992 through 2015.

Meeting the growing demand for a college-educated population will require higher levels of participation and completion from the growing populations which have historically been underrepresented and underserved by the state's system of higher education.

Given the individual and societal benefits of a college education and the anticipated demand for greater numbers of college-educated individuals, it becomes 
important to explore the differences in academic achievement that occur along racial and ethnic lines and how the gaps between groups can be closed. Identifying effective practices and approaches for different student populations has the potential to more effectively direct resources and efforts that result in greater student success among those populations which have historically been excluded from higher education. as the benefits of post-secondary education accrue more widely to those historically underrepresented populations there are greater opportunities for broader individual and societal gains.

\section{Context and Background of the Problem}

The exploration of relevant research can help inform practice and policy to promote equity for students from historically underserved groups who are experiencing lower rates of college success. One of the least studied populations in higher education is those with ethnic and cultural roots in the islands of the Pacific (Mueses \& Kiang, 2009). Despite their growing numbers, census data in Table 1 shows that the levels of post-secondary educational attainment by the Oceania population continues to trail that of their White and Asian counterparts and is similar to those of other historically marginalized groups such as African-American and Latino students (Museus \& Kiang, 2009). As such, educational outcomes for Oceania students can be considered a key measurement of equity. 
In labeling the population from the islands of the Pacific, the U.S. census uses the demographic category Native Hawaiian or other Pacific Islander (NHPI). NHPI refers to a person having origins in any of the original peoples of Hawaii, Guam, Samoa, or other Pacific Islands (United States Census Bureau, 2010). However, in their introduction to Indigenous Statistics, Walter and Anderson (2013) point out that adoption of the nomenclature of the dominant culture by majority, non-indigenous researchers is not a neutral act but reinforces dominant perspectives. Thaman (2001) and other critical Pacific studies scholars have preferred the use of the term Oceania over NHPI as a term that is more culturally and geographically inclusive (Hau'ofa, 1993). Therefore, when not directly quoting, this study uses the term Oceania in place of Native Hawaiian or other Pacific Islander when referencing the people and populations of the islands of the Pacific.

Colonization of Oceania by European and American powers left a mark on education in the region. European and American colonial powers dominate the pedagogy and curriculum of Pacific populations (Hau'ofa, 1993; Kahaleole Hall, 2008; Thaman, 2003). The continuing influence of the imported curriculum from Europe and America prejudices western content and approaches, and devalues traditional knowledge and ways of learning (Thaman, 1998). The legacy of educational colonialism continues to follow Oceania populations as they journey to points in the United States seeking economic and educational opportunities (Kupferman, 2009; 
Martinsen, 2017; Yeh, Borrero, Tito \& Petaia, 2014). As the Oceania student population grows in California and the state seeks equitable outcomes among students, it will become increasingly important to develop educational approaches which are culturally inclusive (Paris, 2012; Museus, 2014) and value the diversity of experiences and backgrounds that students possess.

California has nearly 350,000 Oceania students, representing one of the fastest growing populations in the state (Campaign for College Opportunity, 2015; Lee \& Kumashiro, 2005). According to the Department of Education, between 1976 and 2008 the aggregated Asian and Oceania populations had one of the fastest rates of increase in post-secondary enrollments (Aud, Fox, \& Kewal Ramani, 2010). The Campaign for College Opportunity (2015) reported that $55 \%$ of Oceania college students begin their college careers at community colleges. Success measures for students using a six-year rate of completion- percentage of degree, certificate and/or transfer-seeking students starting first time in 2010-11 who completed a degree, certificate or transfer-related outcomes, shows Oceania students have an overall completion rate of $42.6 \%$ which is similar to rates for African American (36.2\%) and Latino (41.1\%) students and below the rate for Asian students (65.1\%) (California Community College Chancellor's Office, 2016).

Research of the Oceania student population in higher education is limited. Researchers have highlighted the dearth of research literature related to this population 
(Lui, 2013; Museus, 2009; Museus, Mueller \& Aquino, 2013). In a 2009 review of multiple significant peer-reviewed journals, Museus found few published articles related to AAPI in the prior decade. Additionally, only one of approximately 1,500 published articles specifically mentioned Oceania populations (Museus, 2009). In searching the literature for this project, the researcher encountered similar outcomes with regards to the amount of published literature that called out Oceania students without including them in a broader demographic of Asian/Pacific Islander. Outcomes for Oceania students have been hidden by the misapplication of the overly broad demographic label Asian American or Pacific Islander (AAPI) or Asian Pacific American (APA) in research data collection (Lee \& Kumashiro, 2005; Museus \& Kiang, 2009). Inclusion in this overly broad, pan-ethnic category has resulted in masking the low rates of academic success among some parts of the Oceania student population.

Research by Museus and Kiang (2009), and Yeh, Borrero, Tito, and Petaia (2014) suggest that the model minority myth - a notion that Asian American students achieve academic success and are not in need of educational support, is part of the reason that the Oceania population is significantly understudied. Aggregation of data under the AAPI identifier makes the Oceania students invisible and fails to recognize them as a marginalized population with educational support needs. This further 
demonstrates the importance of disaggregating data and the need for conducting more research on the educational experiences of Oceania students.

When student data is disaggregated and Oceania students are viewed outside of the pan-ethnic AAPI or APA demographic, significant differences between groups is apparent. The UCLA Asian American Studies Center (2006) disaggregated data between Asian and Oceania populations and showed disparities between the two groups, especially as it related to University of California admissions, as only 11 of the 4809 new freshmen students at UCLA identified as Oceania. Looking more broadly at educational attainment, Bachelor's Degree attainment levels for the pan-ethnic AAPI group were $52 \%$, (Aud, Fox, \& Kewal Ramani, 2010) which is greater than the general U.S. population rate in 2009 of approximately $28 \%$ (National Center for Education Statistics, 2015). However, when information on degree attainment is disaggregated, it reveals Bachelor Degree attainment rates of $14.4 \%$ for Oceania, well below the national average and comparable to degree attainment rates for Hispanic (12.7\%) and Black (17.7\%) students (National Center for Education Statistics, 2015).

The Oceania population is expected to grow significantly in California, and while these students currently represent less than $1 \%$ of the California community college population (California Community Colleges Chancellor's Office, 2017), they deserve equitable access and opportunity to succeed at college. The projected increase in the Oceania population at California Community Colleges and a lack of available 
research literature suggests an important need for additional studies of practices that can positively impact academic outcomes for Oceania students in higher education. One such practice, that has shown promise at addressing the inequitable outcomes for some marginalized populations, is validation (Rendón, 1994; 2002). The research conducted for this study explored the validation experiences of Oceania students enrolled in a California community college and sought to identify relationships between validating interactions with faculty and other institutional actors and their relationship to students' academic outcomes and persistence.

Student departure from college has been studied extensively (Braxton et al, 2002; Pascarella \& Terenzini, 2005; Tinto, 1993). The dominant theory is Tinto's $(1987,1993)$ interactionalist model, which argues for a relationship between the extent to which students integrate into the academic and social structures of the institution and their decision to persist (Braxton, 2000; Crisp, Taggart \& Nora, 2015). In Tinto's model, academic and social integration are vital to the persistence, and ultimately the success, of college students.

While academic and social integration have been effective for predicting successful outcomes for some populations (Bers \& Younger, 2014; Rocconi, 2010; Tinto \& Russo, 1994; Zhao \& Kuh, 2004), Tinto's model of persistence has been challenged due to its limited applicability to populations of non-traditional, underrepresented, or minority students (Guifrida, 2006; Tierney, 1992, 1999). There is 
growing understanding that the influence of integration on the decision-making process for persistence varies for historically underrepresented and underserved students. Those students find it difficult to integrate into academic and social systems to which they have little connection (Kuh \& Love, 2000) and which marginalizes their experiences and instead is a reflection of the knowledge and values of the, typically White, middleclass dominant cultural groups (Guiffrida, 2006; Liu \& Liu, 1999; Rendon \& Jalomo, 1995; Tinto, 2006).

Rendón's $(1994,2002)$ research suggests that for historically underrepresented and underserved students, validating actions by in- and out-of-class agents had a significant positive impact on students. Validating experiences which respect and value the personal and academic backgrounds of students from historically underrepresented and underserved backgrounds can positively impact students' integration and act as a protective factor in marginalizing environments (Barnett, 2011; Hester, 2011; Hurtado, Alvarado \& Guillermo-Wann, 2015).

The design of the research for this study was intended to explore the validating experiences of Oceania students enrolled in a California community college, and to identify relationships between validating interactions and how they may correlate to students' integration, academic outcomes, and persistence. This study is based on Rendón's (1994) proposition that when students feel validated they perform better on academic measures of success and are more likely to continue their enrollment in 
college. This study uses the concept of validation and explores its relationship to Oceania students enrolled at a California community college and their perceptions of validating experiences with college personnel including faculty and other institutional actors (i.e. staff).

\section{Purpose of Study}

The purpose of this study is to examine Oceania students' perceptions of validation experiences at a public, community college and explore correlations between their perceptions of validation and their integration, academic outcomes, and semester to semester persistence. Specifically, this is a quantitative study to assess and discuss the impact of college encounters using a quantitative framework of validation (Rendon, 1994). The study is based in the proposition that when Oceania students feel that they are valued and treated as capable college students by college personnel (validated) they have a greater level of integration, are more likely to perform well on academic outcomes as measured by GPA, and units completed, and more likely to remain enrolled in college.

The review of the literature suggests that Oceania college students have encountered educational experiences which negatively impacts their perceptions of the campus environment and outcomes. The dearth of literature concerning Oceania and the limited number of quantitative studies exploring validation presents an opportunity for 
this study to further the understanding of how validation impacts the student experience and possibly leads to improved educational outcomes.

Determining whether there is a correlation between validating experiences and integration, academic outcomes and persistence for the Oceania population may inform campus environment, policies, and practices to better serve and support this important, emerging population. This study serves a need to increase the visibility of Oceania students and recognize their unique challenges, which have implications for practice or policy development. Also, because the use of quantitative measures in the study of validation is relatively new, the study may further support this methodology in future studies that could be more generalizable to other or broader populations.

\section{Research Questions}

To explore the research questions, this study uses a quantitative approach. While most prior studies of validation have been qualitative, quantitative analysis of validation is an approach that can be used to evaluate validation's impact on academic success and persistence and to possibly be generalizable from one setting to another (Rendón Linares \& Munoz, 2011).

The specific research questions addressed were as follows:

1. To what degree do Oceania students feel validated by college faculty within the classroom? 
2. To what degree do Oceania students feel validated by other institutional actors outside the classroom?

3. What is the relationship between perceived validation experiences and the sense of competent membership/integration of Oceania students?

4. What is the relationship between perceived validation experiences and the short-term academic outcomes of Oceania students?

\section{Definitions of Key Terms}

Validation, Competent Membership, Academic Success, and Persistence are key terms within the research questions which may not be clear and therefore need to be defined. Validation, as defined by Rendón (1994), is “An enabling, confirming and supportive process initiated by in- and out of class agents... When validation is present, students feel capable of learning; they experience a feeling of self-worth and feel that they....are accepted and recognized as valuable" (p. 44). In this quantitative study, validation was operationalized through a summed index of student perceptions of validating experiences by faculty and other institutional actors, based on survey responses.

Integration is a key concept in the dominant model of student departure and is suggested as a vital component in the student decision to persist (Tinto, 1988, 1993). Tinto (1993) described integration as a sense of competent membership which derives, partially, from student interactions with faculty and other institutional actors. For this 
study, integration is measured through the Competent Membership index. Competent Membership is used to measure student integration and incorporates both students' perceptions of belonging to social and intellectual campus communities as well as belief in their ability to be successful in the college environment (Tinto, 1993; Barnett, 2011).

The use of Academic Success can be vague and it is often used in comparisons of one population with some other population and can integrate different elements such as grade point average, course success rates, degree completion, etc. Operationally Academic Success was used as a dependent variable in this correlational study and measured by cumulative grade point average (GPA), and the number of units completed by students and Persistence.

For this study, the use of Persistence was chosen, rather than Retention, as a more student-centered expression of a decision to re-enroll at the same institution, in the often marginalizing and invalidating environments of community colleges. This is in contrast to Retention, which is an institutional measurement not addressed in Tinto's (1993) student departure model.

\section{Assumptions and Limitations}

In conducting this research, some practical limitations emerged. One significant element is a perpetuation of the error of aggregating data. While understood to be a heterogeneous population, Oceania students were not disaggregated by generation - meaning immigrant or children of immigrants, or geographic/ethnic 
background i.e. Samoan, Tongan, Native Hawaiian. Grouping students from diverse cultural and historical backgrounds into an all-inclusive Oceania population fails to recognize that students with roots in Samoa, Tonga or Hawai'i each have unique cultures, histories of colonization and migration as well as educational backgrounds. Also, some students in the sample were of a mixed ethnic background so intersections of those backgrounds and how experiences may have been different were not explored. However, the limits of institutional data collection, number of respondents, and time necessitated making this choice.

Aside from aggregating data, further limitations include that research was conducted at a single, public community college and took place within a single academic year. The Oceania student population as a percentage of enrolled students at the research site $(2.28 \%)$ is larger than the overall rates across California community colleges ( $0.49 \%$ ) (California Community College Chancellor's Office, 2017-b). The number was part of the justification for studying the Ocean population at this site as it was large enough for meaningful statistical analysis. The measure of persistence was also limited in that it only measured registration from the fall to subsequent spring semester. A longer term study that was able to follow students to determine whether they attained their educational goal - certificate, Associate's degree or transfer, would provide a better understanding of the lasting impacts of validation. Given the limitations 
of sampling, single institutional representation, and short time horizon findings should not be assumed to be generalizable to other institutional types or locales.

\section{Summary \& Organization of Dissertation}

California community colleges provide access to post-secondary education and career training for millions of students. A critical step in achieving educational goals is successful course completion and continuing to enroll in college. There are both financial and personal benefits to the individual and broader society to a more highly educated population and there is a projected need for more college-educated individuals entering the workforce. In order to meet those projected needs and to reap the benefits of our country's investment in education, we need to identify practices which can close the gaps in achievement for the large percentage of historically underserved and underrepresented minority students who are enrolling in our community colleges.

The educational experiences of Oceania students are poorly understood due to the dearth of research on this population. Their invisibility in research literature reinforces the importance of including Oceania in the body of research regarding factors which support student success. This research reviews relevant literature on the historical experiences of Oceania students in education as it relates to colonization and the Pacific diaspora. It continues on to review the challenges of mis-aggregating Oceania student data with students of Asian descent and factors which support academic success. The research explores the dominant theory of student departure and how validation can 
serve as a framework to understand and improve the success and persistence of Oceania students. Findings from analyzing data are discussed in chapter four. Chapter five offers discussion and interpretation of findings as well as recommendations for practice, future research and channels for disseminating this study. 


\section{Chapter Two: Review of Relevant Review}

This review presents literature exploring the educational experiences of Oceania students in relationship to their integration, academic success, and persistence in higher education. The review of literature used a range of strategies to identify resources in the relevant subject areas with special attention paid to identifying references to validation experiences. Key terms such as Oceania, Native Hawaiian or Pacific Islander, academic success, education, and community college were searched using EBSCO, JSTOR ProQuest, and Google Scholar to identify books, print and electronic journals, and relevant dissertations. Branching was used in searching the bibliographies and reference sections of significant articles which often provided additional relevant sources of information. Even with these search strategies, the amount of published literature on Oceania students in the United States higher education system is limited. Museus' review in 2009 of peer-reviewed journals produced minimal results and Yeh's (2004) exploration of Asian Pacific student persistence produced equally low numbers of theoretical and empirical articles. Therefore, this review includes literature from primary and secondary education studies as well as drawing from studies of other historically underserved student populations with similar academic outcomes.

In the literature, which spans multiple decades, various terms were used to describe student populations. The terms used to label students have varied from "minority" to "underserved" to "students of color" to "underrepresented." While in 
some ways distinct, these terms are frequently used interchangeably and many populations exist in the intersections of these terms; this can be confusing when referencing studies which use these different terms to identify the same groups of students. For purposes of clarity when discussing the literature, this review will use the term historically underserved students to refer to the broad category of students of racial and ethnic backgrounds who have historically been underrepresented or underserved in the United States educational systems.

In order to more fully understand the Oceania student population in this study, the relevant literature includes a discussion of the historical context of the influence of colonization and Oceania diaspora on their educational experiences. Following the historical context is a review of the literature concerning Oceania students in the American education system, including challenges with aggregating Oceania student data with students of Asian descent. It provides a review of Tinto's (1993) theory of student departure - the dominant theory of why students leave college before reaching their intended goal and how Rendón's (1994) validation construct can be used as an alternative lens for understanding how student interactions with colleges and universities can lead to increased academic success and persistence.

\section{Historical Context}

Colonization of Oceania. European powers began exploring the Pacific region in the sixteenth century and through economic, religious and military expansion, much 
of Oceania was under colonial rule by Europe and America by the early twentieth century (Spickard, 2002). The principal colonial rulers of modern South Pacific countries were America and the United Kingdom (Britain) with a few French territories. Germany played an early role but by 1914 had lost its territories (Bray, 1993). The legacy of colonization of Oceania by Anglo-European and American powers can be seen today in many of the educational approaches in the region. Anglo-European and American colonial powers dominate the pedagogy and curriculum of Pacific populations (Hau'ofa, 1993; Kahaleole Hall, 2008; Thaman, 2003). Reviewing the colonial history of education in Oceania helps to provide an understanding of the current state of education for Oceania students. Brookfield (1972) as quoted by Bray (1993, pp 334) defined colonialism as the:

deliberate penetration of a local or 'residentiary' system by the agents of an external system, who aim to restructure the patterns of organization, resource use, circulation, and outlook so as to bring these into a linked relationship with their own system.

The early colonial interactions with the peoples of Oceania placed the responsibility for the education of indigenous populations in the hands of missionaries and colonial governments. Colonial and missionary schools were set up with to meet the needs and goals of the colonizing powers and missionaries (Bray, 1993; Hau'ofa, 1993). While the missionaries' goals were frequently to convert the indigenous people to 
Christianity (Eves, 1996; Hau'ofa, 1993), the colonial governments were interested in producing local workers to fill jobs in colonial bureaucracies (Burnett, 2002; WatsonGegeo \&Gegeo, 1992) and accelerate economic development (Lingam, Burnett, Lilo \& Lingam, 2014). The imported, Western-centric curriculum served the interests of the colonizing powers to the detriment of traditional education and practices of the local populations (Lingam, Burnett, et al, 2014; Thaman, 1993; Watson-Gegeo \& Gegeo, 1992).

Colonizing educational practices continued well into the $20^{\text {th }}$ century and were not limited to those Pacific island countries which were colonies. Tonga was never formally a colony; however, as Thaman (1993) describes, in 1947 the Tonga High School was established with a curriculum where English was the language of instruction and use of Tongan while at school was prohibited. While many Pacific island countries took on their own curriculum development, Bray (1993) and others (Lingam, Burnett, Lilo \& Lingam, 2014) confirm that much of the school structures and instruction remain strongly influenced by Anglo-European and American concepts. In extended studies of the Solomon Islands, Watson-Gegeo and Gegeo (1992) noted the school structures had significant societal impacts, including growing class divisions and rejection of traditional teachings. Lingam, Burnett, Lilo, and Lingam (2014) found in their later study of curriculum reform in the Solomon Islands that contextually relevant and locally 
produced materials were perceived to be superior and of higher quality by local teachers.

The history of colonization in Oceania and the continued use of Westernfocused curriculum in the education systems has invalidated the traditional knowledge and ways of teaching among Oceania in spite of curricular reform efforts. The colonization of the primary and secondary education systems in Oceania further complicate the continuing educational experiences of those who leave the region to pursue postsecondary education in places such as Australia, New Zealand, and the United States. Stories passed down from older generations about the devaluing of Oceania knowledge, history and traditions still resonate in the minds of current students (Martinson, 2018). Education has become a driving force for Pacific diaspora (Spickard, 2002); however, for some, the effects of colonization are still felt.

The role of diaspora. As colonial powers engaged with the Oceania populations throughout the eighteenth and nineteenth century, economics, colonialism, and war created navigable routes globally for Oceania peoples. Oceania labor, some voluntary and some slave-like, could be found in trade, fishing, and mining industries wherever colonial interests were in need of labor (Spickard, 2002). Many of those laborers returned to their homes while others remained in places like Australia, New Zealand, and the United States. However, immigration in large numbers to these Western 
population centers began in earnest during the second half of the 20th century (Spickard).

The American presence in the Pacific during and after World War II provided links and paths for Oceania people to come to the United States. For example, the Compacts of Free Association allow most residents of Micronesia- the Federated States of Micronesia, Marshall Islands, Republic of Palau, to freely immigrate to live and work in the United States. Kupferman (2009), cites Ward (1997, pp 186) in describing patterns of Oceania migration to the United States as being similar to rivers which, divide and then rejoin in a web of interconnected channels". In this way, networks of immigrants from particular islands or island groups tend to create "new islands" in their adopted homelands all the while retaining their connections with their home island communities (p. 2).

Even as the migrating Oceania population has moved to the United States there continues to be a significant importance placed on the close cultural, familial and religious ties that maintain the cultural assets and identity (Yeh, Borrero, Tito \& Petaia, 2014) that sustain Oceania through the legacies of colonialism.

The dominant American story of immigration from Europe is one of assimilation. However, the Pacific diaspora is much more recent and provides access to modern technologies such as telephone and internet. The available technology helps to produce what Clifford (1994), quoting Rouse, identifies as a "continuous circulation of 
people, money, goods, and information." (1991, p 303) and supports the diasporic Oceania population maintaining relationships with their homelands, family, and culture to a degree that earlier, assimilated groups have not (Clifford 1994; Gershon, 2007). Safran identified the general characteristics of diaspora as, "a history of dispersal, myths/memories of the homeland, alienation in the host country, desire for eventual return, ongoing support of the homeland, and a collective identity importantly defined by this relationship" (1991, quoted in Clifford 1994, 305). Morton (1998) argues that Tongan migration exhibits diaspora characteristics including a collective identity and continued support for those still living in Tonga. Gerson (2007) points out how diasporic Tongans in California had adapted to their new homeland. Life events such as births and weddings become the opportunity for demonstrating familial allegiances and maintaining family networks and often churches have replaced villages as centers of civic ceremony and spaces where youth learn history, language and cultural traditions (Yeh, Borrero, Tito \& Petaia, 2013).

Oceania diaspora flows largely from colonization. Policies and agreements about the movement of migrants following World War II have provided paths for Oceania populations to migrate to American population centers, often in pursuit of educational opportunities (Heine, 2002; Kupferman, 2009). As Oceania students continue their education in the United States, the differences in education systems, as well as the lingering impact of colonization reflected in mainland education systems, 
add to the marginalization of Oceania students. In the new host countries, differences in cultural norms become racialized and Oceania students are othered in ways that are evident in the curriculum and pedagogy (Kupferman, 2009; Thaman, 2003; Yeh, Borrero, Tito \& Petaia, 2014).

\section{Mis-aggregating Oceania Students in the American Education System}

There is a limited amount of published research on Oceania students in American institutions of higher education (Lui, 2013; Museus, 2009; Vaught, 2012; Yeh, 2004). There may be multiple reasons for the deficiency of research but a significant one is that much of what is published tends to aggregate Oceania students into a broader Asian American and Pacific Islander (AAPI) or Asian Pacific American (APA) category (Lui, 2013; Teranishi, Behringer, Grey \& Parker, 2009; Yeh, 2004). This invisibility is a failure to recognize Oceania as a unique population with diverse within-group differences.

The struggle for recognition of Oceania is not new (Hall, 2016). Hall describes coalitions between Asian and Pacific Islanders beginning primarily in California and built around political movements of peoples who had been historically exploited and marginalized in the United States. The 1977 Office of Management and Budget directive to collect data based upon a racial category of Asian or Pacific Islander was the beginning of tying together these two completely different groups for official purposes and separating them has been difficult. Even though the current government 
standards differentiate between Asian and Native Hawaiian and other Pacific Islander categories the conflation of the groups continues (Hall) and only serves to perpetuate the invisibility of Oceania.

Continuing to aggregate Oceania students with those from the East Asian countries is problematic due to the larger numbers of East Asian students in American higher education institutions and a longer educational history in those institutions (Makuakane-Drechsel \& Hagedorn, 2000; Museus \& Kiang, 2009; Yeh, 2004). The result is that research involving the Oceania populations typically occurs within the broadly inclusive AAPI/APA demographic. Due to the larger numbers of students from the East Asian countries of China, Japan, and South Korea, details of the smaller the Oceania population are overwhelmed and their circumstances are hidden. Aggregation of Asian American and Oceania students masks the low educational achievement rates of Oceania students within the relatively high rates of the larger Asian American student population (see Table 1).

When data regarding Asian American and Oceania students is disaggregated, it shows the differences in outcomes between the groups and gives a clearer understanding of the educational experiences of Oceania students. For example, Pang, Han, and Pang (2011) completed a study of Asian American and Oceania seventh graders in California. They disaggregated the data for more than 1 million Asian, Oceania, and White students by ethnicity, and then compared their reading and math 
achievement levels. The findings show Chinese, Japanese and Korean Americans had higher levels of achievement in both reading and math than Oceania students. Comparisons between White students and Oceania students also showed the Oceania students performed significantly lower in both math and reading (Pang, Han \& Pang, 2011). This large-scale quantitative study only looked at math and reading achievement outcomes of primary school students; however, disaggregating data and showing the differences in outcomes of Asian American and Oceania students, suggests a need for further understanding of the experiences of Oceania students and factors that may be contributing to their academic achievement levels.

Model minority myth and failure to disaggregate. Failing to disaggregate data on Asian American and Oceania students is, in part, a consequence of the model minority myth (Museus \& Kiang, 2009; Teranish, Behringer, Grey \& Parker, 2009). The model minority is a mistaken stereotype that frames Asian Americans as being high achieving students who are not in need of support. It is often used as a way to suggest that racism is not embedded in institutional or systemic systems since Asian Americans are able to achieve academically at high levels, presumably through some cultural or character strength (Lui, 2013; Poon et al, 2016). The model minority myth impacts perceptions of many subgroups including those from south-east Asia, Indonesia and Oceania (Museus, 2009). Each group has its own unique challenges, however, this study and the literature reviewed focused on Oceania. The inclusion of Oceania in the AAPI 
demographic leads to their inclusion in the model minority stereotype, which can suggest that high academic achievement reflects the conditions of all ethnicities within the group (Makuakane-Drechsel \& Hagedorn, 2000; Pang, 2007) further marginalizing and hiding the Oceania students.

The model minority myth obscures the experiences of Oceania students who are subject to its application (Lee \& Kumashiro, 2005; Museus \& Kiang, 2009). The stereotypical image of the AAPI/APA model minority myth, which Oceania is often counted as part of, is predominantly that of the studious and hardworking Asian American student (Choi, 2010; Poon, et al., 2016; Rohrlick, Alvarado, Zaruba, \& Kallio, 1998). The reality of what Oceania students experience is a contradictory stereotype. Poon et al. (2016), in their critical race definition of the model minority myth, identified two interconnected elements in the racialized generalization of Asian American success. The first is that "Asian Americans are strategically presented as a model of self-sufficient minority success. Second, the stereotype of success among Asian Americans is used to blame another minority group for its struggles..." (pp 474). Thus when Oceania students do not live up to the mythical academic standards of the model minority they are either ignored and hidden within the aggregated data (Museus \& Kiang, 2009) or Oceania students are labeled with a different stereotype, that of the deficient minority who does not value education (Gorski, 2008; Vaught, 2012; Yosso, 2005). 
Some of the negative impacts of the deficient stereotype are explored by Borrero, Yeh, Tito, and Luavasa (2010) in their study of the academic and cultural identities of Samoan high school students. In that study, Samoan student interviewees identified the most common stereotypes they experienced were as, "physically large, athletic, strong, lazy, proud, and dangerous." (pp 51). In a separate qualitative study of older cultural insiders within the Samoan community, participants expressed concern over how the stereotypes students confronted were manifesting within the schools as racism and discrimination (Yeh, Borrero, Tito \& Petaia, 2013). The older participants were Samoan counselors, case managers, and coordinators at a community based organization. They felt that Samoan students faced disproportional suspension and placement in the lowest levels of academic courses. They also thought that there was a lack of institutional initiative to recognize Samoan culture, its cultural strengths and how their values- unity, family responsibility and respect, generosity and protecting others, are incorporated into students' academic lives.

It is important to call out the role that aggregating data and the model minority myth have played in promoting invisibility and stereotypes that result in a lack of research of Oceania at the systemic level. It is equally as important that, as Poon et al. (2016) suggest, many of the counter arguments to the model minority myth can play into deficit model thinking because they highlight the contrasting low performance of Oceania students relative to the Asian American students. So rather than just calling out 
the need for disaggregating data, it is equally important to identify and bring attention to the systemic and institutional structures that lend themselves to continued oppression and marginalization of Oceania students. Policies that assume Oceania students are not encountering racial barriers and are not in need of academic supports stand in stark contrast to the image that forms when data is disaggregated and the voices of Oceania are heard about their educational experiences. Understanding the reality of their experiences can provide a better understanding of the factors which support or hinder academic achievement of Oceania students.

\section{Academic Achievement Factors}

One of the institutional factors contributing to lower success rates may be attitudes and beliefs of educators which manifests in the marginalization of Oceania students on campus. Campus climate and discriminatory experiences of historically underserved students can have a negative impact on the persistence of racial minority students (Museus, Nichols \& Lambert, 2008). This was evidenced by Samoan high school students, who reported having to overcome stereotypes and the low academic expectations of school personnel in order to feel academicaily successful (Borrero, Yeh, \& Tito, 2010). Additional research by Vakalahi (2009) also found high school respondents confronting perceptions by school staff and students that Oceania students were "troublemakers and dumb" (p. 1261). The attitudes and beliefs of institutional 
actors and peers can make educational environments unwelcoming and demotivating for Oceania students.

Contributing to the unwelcoming environment are those institutional actors who have a deficit mindset. Educators with a deficit mindset may believe that Oceania culture does not value academic performance to the same degree as some other racial or ethnic cultures (Dee \& Penner, 2016). Solarzano and Yosso (2001) referred to this as having a "cultural determinist" (p. 5) view which frames inequitable outcomes as deriving from the cultural values and related behaviors of historically underserved student populations. For those with this mindset, the solution is having historically underserved students acculturate to the cultural and behavioral norms of the dominant, and better performing, student groups. Research by Vakalahi (2009) and Yeh (2004) identified familial and cultural demands of time and resources as possibly exerting a negative influence on the academic life of Oceania students. However, Vakalahi (2009) also showed that family expectations and peer influences could act as sources of protection against school departure for Samoan high school students. While Yeh (2004) identified family demands and cultural adjustments to be challenging for those Oceania students relocating to the mainland United States, difficult cultural adjustments fail to account for Lee and Kumisharo's (2005) observation that, "Compared to other major ethnic groups in Hawai 'i, Native Hawai'ian students have the lowest graduation rates and are overrepresented in special education" (p. 4). The finding that Oceania students 
are performing at lower rates even in Hawai'i suggests that there are other factors influencing outcomes than just familial demands or cultural adjustments. While many of these studies were of high school students, it is reasonable to expect similar stereotyping and mistaken beliefs happening on college campuses and shaping the experiences of Oceania students in higher education.

The institutional role in supporting students is undermined when students are marginalized and delegitimized as capable students. Yeh (2004), in studying the persistence of Asian and Oceania college students, states a need for institutions, "to acknowledge their part in contributing to student retention and persistence" (p. 89). The implication is that educational institutions need to take steps to reshape the marginalizing institutional environments confronting Oceania students as they strive for academic success.

Despite negative stereotypes and marginalizing experiences, many Oceania students want to pursue postsecondary education and those who do are often the first in their families to attend or even consider attending college. Unfortunately, their interest in continuing their education beyond high school has not translated into enrollment in postsecondary institutions. In a report to the Washington State Commission on Asian Pacific American Affairs, Takeuchi and Hune (2008) found that while nearly half of the Oceania students in the study aspired to attend college, that number was still notably lower than the percentage of non-Oceania students in the study with similar aspirations 
(76\%). As part of a one-year follow-up of the same students, comparisons were done between the initial percentage who aspired to attend any college and those who had enrolled. Takeuchi and Hune (2008) found large percentages of Samoan, Native Hawaiian, and other Oceania students had not fulfilled their plans. For example, while $68 \%$ of Samoan students had indicated an intent to enroll in college, one year after high school only $44 \%$ had done so. The percentages were even lower when looking at intent and actual enrollment at 4-year colleges. Less than $50 \%$ of the respondents indicated an intent to attend a 4-year college and one year later less than a third of the Oceania students had enrolled at a 4-year institution. The decision to attend college is complex and impacted by the educational experiences of current Oceania students as well as those of their parents and grandparents, as the negative impact of marginalization in a colonized curriculum is passed from one generation to the next.

Despite the lingering effects of colonial practices continuing to impact the educational experiences of Oceania students, the research from Washington (Takeuchi \& Hune, 2008) suggests there is a significant interest in post-secondary education among the population. Individual, as well as institutional factors, can marginalize and invalidate students; therefore, it is important to understand factors which may contribute to improving rates of persistence for those among the Oceania students who do enroll in post-secondary education.

\section{Persistence}


Early student departure is the act of students leaving a college or university before reaching their intended goal. Continued enrollment is a necessary element of completing degrees or transferring from community college and persistence is a common measure of academic success (Bragg, 2001). Definitions of persistence in the research literature are inconsistent, as it is often measured at different intervals depending on the research being conducted or data being provided. For example, the authors of The Condition of Education 2017 report (NCES, 2017) measured it as the percentage of college students who were still enrolled in college or had attained a certificate or degree after three years. Other research measures it as when students are enrolled from one year to the next or if students departed an institution but remained in the system of higher education by transferring to another institution (Tinto, 1993). In research about student success, persistence is a common measure of academic success and in the context of this study was operationalized as students continued enrollment at Midsized Community College (MCC) from the fall semester to the spring semester.

With growing numbers of historically underserved students enrolling in 2-year and 4-year colleges, exploring the reasons for early student departure from college can help postsecondary institutions evaluate policies and practices, and direct resources to improve retention efforts for those student populations experiencing early departure (Aud, Fox, \& Kewal Ramani, 2010). The dominant theory regarding early student departure from college is Tinto's (1993) interactionalist model (Braxton, 2000; Crisp \& 
Nora, 2015; Pascarella \& Terenzini, 2005) that looks at both the individual studient as well as the institution. Tinto's (1993) model emphasized the importance of social and academic integration on student departure and academic success. Tinto's model of departure evolved from studying patterns of college dropouts from which he developed a model of college student attrition that theorizes students have greater rates of persistence and degree attainment when they are integrated into the academic and social life of the college.

While recognizing that students enter college with different pre-college characteristics, Tinto's model is structured around college students' need to separate from their previous backgrounds, transition to the culture of their campus, and finally integrate with the academic and social communities of the college. By integrating with the academic and social systems of the institution, students' levels of commitment to their goals and the institution are increased, which in turn raises their likelihood of completing their academic goal. Integration, as Tinto (1988) described it, involves students establishing "competent intellectual and social membership in the communities of the college" ( $p$ 447). Failing to integrate or become competent members of the academic and social communities of the college, causes many students to leave. Competent membership is used by Tinto (1988) to describe the final phase of student integration as they interact with members of the campus community and establish themselves as participating members of their new environment. Implied in Tinto's 
(1993) model and more explicitly expressed by Barnett (2006) is that competent membership incorporates a students' sense of being part of campus communities as well as a belief in their own academic ability to succeed in college. Tinto (1993) concluded that students' level of integration has a strong influence on persistence and that what happens to students in their interactions within the college environment is of greater salience than their pre-entry characteristics. He suggested that leaving college reflects a student's inability or unwillingness to integrate into the college community.

Figure 1. Tinto's Longitudinal Model of Institutional Departure from Leaving College: Rethinking the Causes and Cures of Student Attrition by V. Tinto, 1993, Chicago: University of Chicago Press

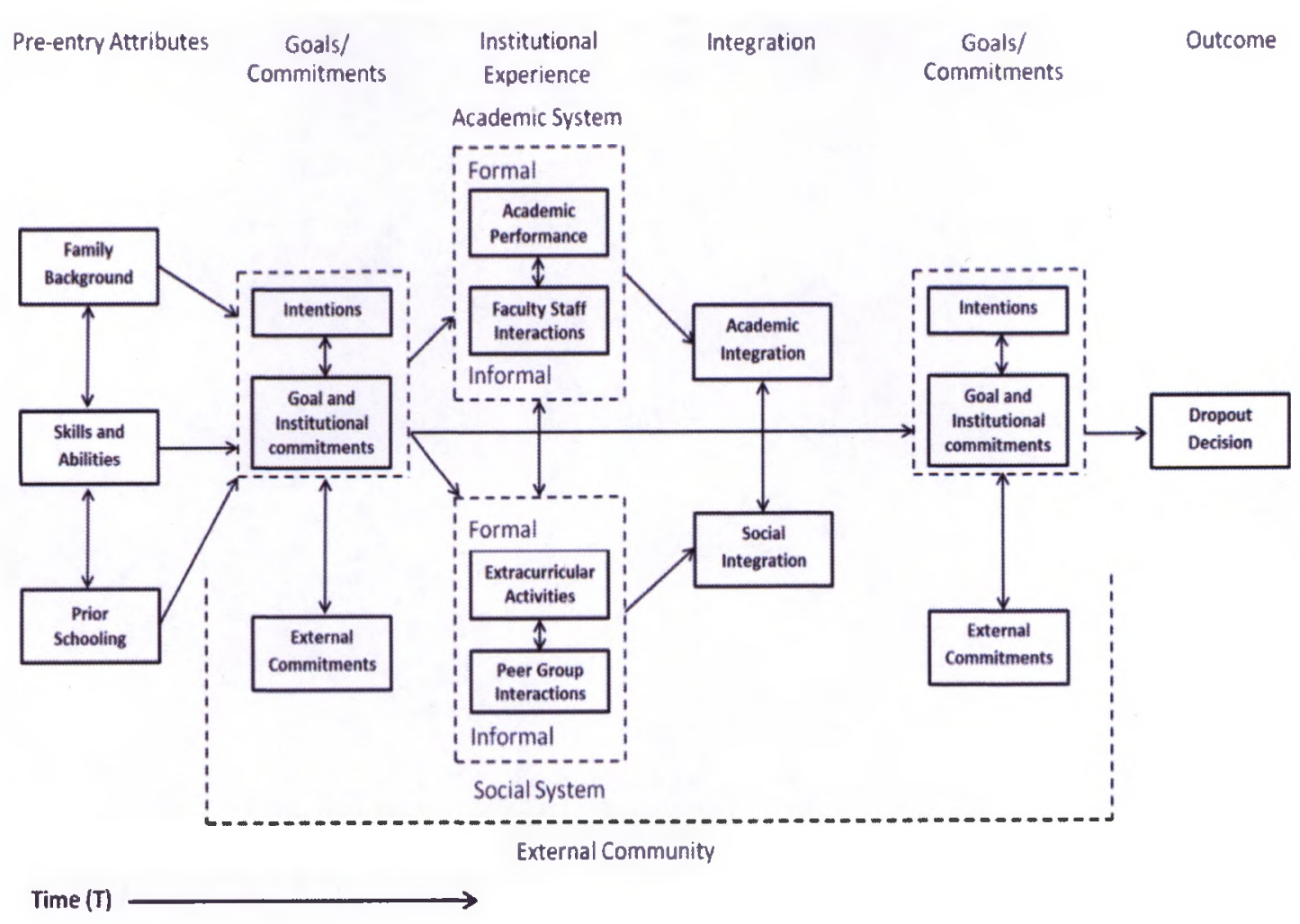


As the dominant model of persistence in higher education (Braxton, 2000; Crisp, Taggart \& Nora, 2015; Hagedorn, 2005), Tinto's theory has been reviewed and tested since it was proposed. Academic and social integration, key elements of Tinto's model, have been effective for predicting successful outcomes for some populations. Berger and Milem (1999) found social integration to have a significant direct effect on persistence $(\beta=.14, p \leq .01)$. Using data from the National Survey of Student Engagement (NSSE), Webber, Bauer Krylow and Zhang (2013) found that higher levels of faculty interactions were positively related to higher grade point averages for first year students. Their results also showed that a greater institutional emphasis on nonacademic support and interaction increased the likelihood of students rating their satisfaction with their academic experience more positively. However, reviews of empirical evidence testing Tinto's model have provided only partial support as it relates to commuter institutions such as community colleges (Braxton, Sullivan, \& Johnson 1997). Braxton, Sullivan and Johnson (1997), derived thirteen propositions testing Tinto's model then reviewed studies that empirically tested those propositions. They identified strong support for two of the thirteen propositions as they related to non-residential institutions. Most community colleges are non-residential, commuter institutions and Tinto's (1993) model assumes an assimilation process which can be inconsistent with the experiences of historically underserved students or those from non-traditional 
backgrounds (Rendon et al., 2000) most of whom begin their post-secondary careers in community college.

Even beyond its application to non-residential institutions, Tinto's (1993) model has been challenged due to its limited applicability to populations of historically underserved students. Central to many critiques of Tinto's model is the "the assumption that minority students must separate from their cultural realities and take the responsibility to become incorporated into college's academic and social fabric in order to succeed..." (Rendon, Jalomo \& Nora, 2000, p. 129). Tinto (2006) recognized his early model as being limited by its focus on traditional 4-year, residential institutions and based upon predominantly white, male populations, but maintained that integration is important for student persistence.

Critiques about assumptions of integration by Taylor and Howard-Hamilton (1995), Tierney (1999) and Rendon et al. (2000) suggest that historically underserved students may be averse to engaging in the academic and social endeavors of the college because historically underserved students do not see themselves reflected in the mainstream campus values and culture. Museus and Quaye (2009), citing Kuh and Love (2000), suggest that the greater the difference between the student's pre-college culture and the dominant college campus culture, the less likely a student is to persist to their second year. However, for many historically underserved students, validating interactions with faculty and staff can help to counter the marginalizing effects of a 
campus culture which does not represent them (Hurtado, Alvarado \& Guillermo-Wann, 2015; Stebleton \& Aleixo, 2015).

The impact of learning communities. The high attrition rate of Oceania students at community colleges has been framed as a problem of low levels of integration (Tinto, 1987; Engle \& Tinto, 2008). Improving persistence for marginalized student groups requires developing college environments that reflect the behavioral norms and values of a broader cross section of students (Berger and Milem, 1999). One strategy growing in popularity among community colleges to promote student integration and positively impact academic outcomes are learning communities (Zhao \& Kuh, 2004; Beachboard, Beachboard, Li \& Adkison, 2011; Weiss, Visher, Weissman, \& Wathington, 2015).

Learning communities take many forms but Gabelnick, MacGregor, Matthews, and Smith, (1990) define them as an intentional structuring of curriculum that connects course work in a way that encourages greater levels of engagement among students and between students and faculty. Learning communities have been demonstrated to have positive impacts on college success with improved persistence, grades and likelihood of graduation, attributed to theories of student engagement and integration in the social and academic endeavors of the college (Astin, 1984; Engle \& Tinto, 2008; Zhao \& Kuh, 2004; Inkelas, Szelenyi, Soldner, \& Brower, 2007). 
Research by Tinto and Russo (1994), Zhao and Kuh (2004) and Rocconi (2010) connected the positive benefits of learning community participation with student integration but did not address that the benefits may accrue differently for different student populations. Berger and Milem (1999) suggest the degree of involvement needed for success is more difficult for minority students, therefore colleges should use strategies that accommodate a variety of cultural differences among students; however, there is little research on their effectiveness for Oceania students.

\section{Validation}

While Tinto's theory of integration and retention is dominant in higher education and suggests that students must integrate in the academic and social life of the campus, some scholars (Berger \& Milem, 1999; Nora, Urick \& Cerecer, 2011; Rendón, 1994; Tierney, 1999) have suggested that non-traditional, historically underserved or marginalized student populations have difficulty integrating, or gaining competent membership, in academic or social systems with which they have little connection. In their review of Tinto's theoretical model, Berger and Milem (1999) suggest it could benefit from additional constructs that could improve its consistency and help identify sources of academic and social integration. Validation could be viewed as one of those supporting theories.

Rendón (1994) defined validation as interactions initiated by faculty as well as other institutional actors (academic counselors and other college personnel) which 
foster a sense of the students' ability to succeed at college. Rendón's validation theory evolved from the Transition to College Project, a qualitative exploration of the effects of student involvement on their learning. The study involved 132 first-year students from diverse racial/ethnic backgrounds from several different postsecondary institutions. Smali group interviews were conducted pertaining to decisions to attend college, expectations, and how students felt college was affecting them. The research identified differences between traditional and nontraditional or historically underserved students. Many of the historically underserved students in the study had come to college expecting to fail. One woman in the study was quoted as saying, "I expected to fail. Two weeks and I was out. I didn't think I could study. I didn't think I could learn" (p. 38). After analyzing over 200 pages of transcripts, the researchers' findings related to the interactions that were transforming students from being doubt-filled and uncertain into more secure, successful learners. The study identified key validating experiences that were critical in fostering the belief among the historically underserved students that they could be successful.

Validating experiences are those actions, initiated by faculty and staff that support a student's belief in their capacity to learn and succeed (Rendón, 1994). In analyzing student responses from the interviews, Validation was found to have the following elements: 
1. Validation is an enabling, confirming, and supportive process initiated by in- and out-of-class agents that foster academic and interpersonal development.

2. When validation is present, students feel capable of learning; they experience a feeling of self-worth and feel that they, and everything that they bring to the college experience, are accepted and recognized as valuable.

3. Like involvement, validation is a prerequisite to student development.

4. Validation can occur both in- and out-of-class. In-class validating agents include faculty, classmates, lab instructors, and teaching assistants. Outof-class validating agents can be 1) significant others, such as a spouse, boyfriend, or girlfriend; 2) family members, such as parents, siblings, relatives, and children; 3) friends, such as classmates and friends attending and not attending college; and, 4) college staff, including faculty who meet with students out-of-class, counselors/advisors, coaches, tutors, teaching assistants, and resident advisors.

5. Validation suggests a developmental process. It is not an end in itself. The more students get validated, the richer the academic and interpersonal experience. 
6. Validation is most effective when offered early on in the student's college experience (Rendón, 1994, p. 44).

Historically underserved students who have been made to feel marginalized are not likely to initiate those validating encounters, inside or outside of the classroom. Rendón (1994) goes on to assert that validating experiences could prove transformative in that they empower; by respecting and recognizing the unique cultural, academic and personal backgrounds of nontraditional or historically underserved students.

Critical to the historically underserved students in Rendón's (1994) study were incidents where someone else took the initiative to help or acted to acknowledge the student's ability to do academic work. This is in contrast to Tinto's (1993) theory which anticipates that students find their path to integration/competent membership and the institution's role is a passive one, merely creating the structures for students to get involved. Rendón (1994) differentiated involvement and validation in the findings and suggested that involvement in campus life was more difficult, and in fact, validation was suggested to be a prerequisite for involvement, for the historically underserved students in the study. At the time, Rendón (1994) was clear that the results were likely not generalizable since there was not a representative sample. Since then, additional research has been conducted using the validation construct, and similar findings have supported its continued applicability and further study. 
The published literature on the effects of validation on educational outcomes is an emergent field of research that supports validation having a positive impact on the academic success of historically underserved students at community colleges. Rendón (2002) studied the validating elements of a community college Puente program - a transfer support program oriented primarily Latino/a students. Through interviews, focus groups, class observations and written narratives, the research explored elements of validation and its impact on students. A central finding was that both academic and interpersonal validation supported students' conficence in their academic ability and that improved confidence was transferable to other classes outside of the Puente program. Both faculty and counselors were identified as validating agents with the personal and intrusive nature of the counselors' involvement in the students' academic endeavors being highlighted as a significant element in the Puente model.

Research connecting validation and persistence, conducted through focus groups and interviews of community college students (RP Group, 2013), identified both faculty and staff as critical influences on students' decisions to depart college before reaching their goals. The role of counselors in validating historically underserved students was the focus of a study by Xiong, Allen and Wood (2016). Their phenomenological study used validation as a theoretical framework for exploring the interactions between community college counselors and men of color. The analysis brought out elements of Rendon's validation model regarding academic and interpersonal validation and show 
the important role that non-instructional faculty play in validating students. The study participants were counselors and it is unclear if Oceania students are identified by the participants as men of color. Still, the study shows elements of the validation construct with institutional actors being proactive in initiating interactions with students which affirmed their capability for academic success and provided students with connections to other validating agents.

A central element of validation (Rendon, 1994) is that supportive interactions are initiated by institutional actors, such as faculty and staff. Stebleton and Alexio (2015) looked at obstacles that undocumented students faced preventing them from developing validating relationships with faculty and other campus agents. Through their interviews, they demonstrated that undocumented students of color faced significant challenges regarding who they could trust with the information of their undocumented status. The uncertainty of how institutional actors would respond to their status made validating relationships, especially between the students and faculty, difficult to navigate. However, when positive, validating experiences with faculty and other campus actors were present, they acted as a positive influence on students' social development and engagement in what were otherwise invalidating campus environments.

The studies done by Rendón (1994, 2002), Xiong, Allen and Wood (2016), and Stebleton and Alexio (2015) were qualitative and explored students' perceptions of their 
validating experiences and how those experiences influenced students' engagement and their identity as capable college students. Supporting the qualitative research is a small, body of quantitative research which corroborates the positive influence of validation on student outcomes, especially as it relates to persistence. Dissertations by Barnett (2006) and Hester (2011) as well as published articles by Barnett (2011), Hurtado, Cuellar and Guillermo-Wann (2011), and Hurtado, Alvarado, and Guillermo-Wann, (2015) using quantitative methods to examine validation suggest that this approach is gaining acceptance and visibility.

Quantitative analysis of validation is a relatively new approach with studies by Barnett (2011) and Hurtado, Alvarado, and Guililero-Wann (2015) employing surveys and quantitative analysis to correlate validation experiences with specific outcomes. In Barnett's (2006) dissertation research, she developed and validated quantitative scales that measured student perceptions of validating experiences by faculty to explore how validation contributed to the students' sense of competent membership and how that may contribute to the intent of students to persist, which she defined as intending to reenroll for the subsequent semester. The research explored faculty-student interactions at "a diverse, urban community college to determine whether students who experience higher levels of validation were more likely to feel integrated, and to express an intent to persist in college" (p. 49). The survey used in the research was designed, tested and validated before being administered in a credit English class and completed by 333 
students at a community college. Data analysis involved multiple linear regression that was used to test several hypotheses and sub-hypotheses regarding validating experiences by faculty on students' integration/competent membership and intent to persist as they related to Tinto's Model of Student Departure (Figure 1). Findings indicated higher levels of faculty validation to be important contributors to a sense of integration/competent membership $(\beta=.724, p<.01)$. Additionally, faculty validation $(\beta=.316, p<.01)$ and competent membership $(\beta=.293, p<.01)$ were both demonstrated to be positive predictors of students' intent to persist at the college. Barnett's (2006) exploratory research on faculty validation and competent membership showed them to be strong to moderate fits as predictors of persistence. While limited to a single institution, the findings support the previous qualitative research on the positive impact of validation on students.

The same survey was adapted by Hester (2011) to complete a dissertation study with a narrower focus on students in STEM fields at a community college and their course-specific validating interactions with faculty in chemistry, math, and physics. Hester's findings indicated that there was a significant relationship between validation and academic success with students who reported a greater sense of validation earning higher grades than students who reported lower validation scores. Both Barnett (2006) and Hester (2011) looked at the influence of faculty validation on academic success measurements but neither explored how students may experience validation from other 
institutional actors, such as counselors or other staff members. Also, neither disaggregated the AAPI data suggesting that results, similar to other research, bias the larger population of students of Asian descent.

Additional quantitative research completed by Hurtado, Cuellar, and GuillermoWann (2011) used a national survey, the Diverse Learning Environments (DLE) survey, and analyzed responses measuring student perceptions of academic validation and general interpersonal validation. The DLE data was collected from a mix of 14 community college and four-year institutions. The final sample size for 4,472 students included a diverse mix of 2,574 self-identified historically underserved students of color, nearly two-thirds of whom were first-generation college students. Data analysis of both in-class, academic validation and general interpersonal validation indicated that the historically underserved students perceived lower levels of both academic and interpersonal validation than the White students who participated. The results support using quantitative means to explore validation as a means to show how it may relate to students' educational outcomes.

In a follow-up study using data from the DLE, Hurtado, Alvarado, and Guillermo-Wann (2015) explored whether validation acts to mediate the effect of discrimination and bias on students' sense of belonging and through that their integration in college. The results showed the "negative direct effect of Discrimination and Bias on Sense of Belonging is substantially reduced and mediated by students' 
validation experiences (Discrimination and Bias from $\beta=-.11$ to $\beta=-.04, p<.001$ ). The combined outcomes of the two studies using DLE data suggest that while historically underserved students may experience lower levels of validation, that validating faculty and staff interactions can assist student integration and bolster students against a discriminatory environment as measured by their greater sense of belonging (Hurtado, Alvarado \& Guillermo-Wann, 2015).

The quantitative studies conducted by Barnett $(2006,2011)$ and Hurtado, Alvarado and Guillermo-Wann $(2011,2015)$ have their limitations, including not fully disaggregating the historically underserved students in the group comparisons and not separating out validating measurements of faculty and staff. Still, they hold value in extending the growing body of research around validation and the use of quantitative measures in researching its influence on student outcomes.

Together, the qualitative and quantitative studies exploring validation support the construct as an intentional process supporting integration, student success, and persistence. Through validating experiences, some historically underserved students are transformed from students who are uncertain about their ability to succeed into college students who have a greater sense of their abilities as learners. While several of the studies referenced involved primarily Latino/a students or other students of color, none were focused on Oceania. Similar circumstances and experiences to those of the populations studied are likely part of how Oceania students experience community 
college and similar benefits would similarly accrue from validating experiences. The implications of the research for institutional actors, including both faculty and staff, suggest that both in-class and out of class actors be more proactive in reaching out to students and that they be more familiar with the realities and needs of students.

\section{Summary and Implications}

Their unique social and immigration histories have shaped the educational experiences of Oceania students. The colonial and immigration histories of those from Oceania have placed them in educational structures that largely ignore or invalidate their experiences and ways of knowing. Aggregation of Asian American and Oceanic students and the model minority myth masks the educational achievement rates of Oceania students within the relatively high rates of the larger Asian American student population. Research into the educational challenges faced by Oceania students in college is limited but what is available tends to focus on outcomes and how they relate to educational risk factors associated with cultural and campus experiences. Studies of the educational experiences of Oceania students suggest that there are institutional influences, such as negative stereotypes and unweicoming campus environments, contributing to lower achievement rates (Borrero, Yeh, \& Tito, 2010; Vakalahi 2009). Although it is reasonable to believe that Oceania students continue to encounter marginalizing environments on college campuses, the pursuit of post-secondary education is still perceived as a means of personal and economic growth and so there is 
a growing number of Oceania students entering higher education, especially in the community colleges. Deficit frameworks that highlight lower Oceania academic performance relative to the dominant White population only serves to further marginalize the Oceania population. To more fully understand this diverse and growing student population, additional research identifying factors that support their academic achievement is needed.

Validation has been suggested as one strategy for mediating the negative effects of marginalizing campus environments. The research literature discussed has examined the theoretical basis and empirical evidence supporting validation as an approach that supports successful integration and academic outcomes. However, there have not been any studies conducted that involve solely the Oceania population and their experiences with validation which leaves open questions about its influence on Oceania students in community college.

From the review of literature related to validation and Oceania, several research questions present themselves which will be explored by this study:

1. To what degree do Oceania students feel validated by college faculty within the classroom?

2. To what degree do Oceania students feel validated by other institutional actors outside the classroom? 
3. What is the relationship between perceived validation experiences and the sense of integration/competent membership of Oceania students?

4. What is the relationship between perceived validation experiences and the short-term academic outcomes of Oceania students?

The information from this study could provide insight into Oceania student experience, and the information derived from the value of validating experiences could be used to facilitate positive institutional changes and professional practices that could lead to increasing the number of Oceania students who persist and achieve postsecondary success. 


\section{Chapter Three: Methodology}

This chapter describes the methodology used in this study, beginning with researcher positionality and a restatement of research questions. The research design, setting, and instrument are then described followed by a discussion of data collection and analysis, validity and ethical considerations.

\section{Researcher Positionality}

Since beginning exploratory research of the Oceania population, I have been challenged to consider positionality and motivation as an outsider to the Oceania community. Insiders can be considered as, "individuals...in the community who have experience and insight associated with being a member of a particular cultural group (Yeh, Borrero, Tito \& Petaia, 2014, p 148). Being a White, Anglo-European, I am challenged to articulate reasons for wanting to research with Oceania students. The challenge is not only to evaluate the reasons for researching Oceania students, a relatively small group, over larger and more visible student populations but why am $I$ doing this research?

Research by White researchers using Western based practices can bias particular points of view and values in the research process and past practices have devalued and Othered indigenous populations (Smith, 2013; Walter \& Andersen, 2013). As a practitioner, I recognize and empathize with the challenges of Oceania students and believe that this study could contribute to 
understanding the academic achievement and the college experiences of Oceania students. However, in that belief, it is important to critically reflect on researcher positioning and issues of power and "outsider" status. Milner (2007) was succinct in stating, "when researchers are not mindful of the enormous role of their own and others' racialized positionality and cultural ways of know, the results can be dangerous to communities and individuals of color" ( $\mathrm{p} 388$ ). Conducting research with Oceania students, it is important to maintain an awareness of the researcher's role as someone why may be perceived as an authority figure within the structure of the college.

Community and familial relationships are important in the Oceania culture. Developing genuine relationships with some key figures in the campus Oceania community communicated the intent of approaching this topic with sincerity and humility; however, it does not negate an awareness of perceptions of standing and position. I anticipated the need for open and honest access to students if I was to collect data through typical qualitative means like interviews or focus groups. However, as Vaioleti (2006) pointed out, responses from students may depend on how they perceive the researcher's age, gender and standing within the context of their own cultural lenses. That awareness is part of what steered me towards a quantitative approach for this study. 
Using quantitative methods presents its own challenges feeding into the argument about applying Western methods and measures to a colonized and still marginalized people which only perpetuates issues of power and imposed standards. Applying a set of quantitative scales to Rendón's validation theory is a previously used methodology (Barnett, 2006; Hester, 2011) that provides an avenue to still explore Oceania student's educational experiences but at enough of a distance that outsider status, while still relevant, seems less invasive (Smith, 2012; Walter \& Andersen, 2013). This topic - the validation experiences of Oceania students and their correlation to academic outcomes - and this quantitative approach will allow a contribution to understanding an important equity question, factors supporting the academic success rates of Oceania students at community colleges.

Research can help inform practice and policy to promote equity for Oceania students as well as other marginalized groups who are negatively impacted by acts of social oppression. Education has served as part of the colonizing structures of Oceania. Seeking to understand the policies and practices that validate Oceania students and perhaps support their success can help to combat situations which, if left unchallenged, can perpetuate colonial, racist/classist structures.

\section{Introduction}


The purpose of this study was to examine the validation experiences (independent variables) of Oceania students at MCC and the relationship of those experiences to the students' academic success and persistence (dependent variables). The study sought to quantify both in-class validation experiences with faculty as well as experiences outside of the classroom with other college agents, such as counselors and staff, through an online survey of Oceania students enrolled at MCC. The process of gathering data was done through the use of an adapted, existing survey instrument. According to Creswell (2013), the use of a survey instrument in the quantitative design of a study is useful in an exploration of factors that may influence outcomes.

The strategy for this inquiry was a survey instrument in which the researcher adapted valid, tested scales from two existing instruments that measure validation from different institutional actors. One instrument was used to measure students' validation experiences with faculty (Barnett, 2011) while the other adapted a sub-scale that measured general interpersonal validation (Hurtado, Alvarado, \& Guillermo-Wann, 2015) by non-faculty members. For this study, students were asked to score their agreement on a series of questions and from those responses, validation indices (independent variable) were derived taking the sum of response scores. For students who responded to the survey, demographic information as well as measures of integration, academic success and persistence were collected (dependent variables).

The research questions that this study sought to investigate are: 
1. To what degree do Oceania students feel validated by college faculty within the classroom?

2. To what degree do Oceania students feel validated by other institutional actors outside the classroom?

3. What is the relationship between perceived validation experiences and the sense of integration/competent membership of Oceania students?

4. What is the relationship between perceived validation experiences and the short-term academic outcomes of Oceania students?

Key terms of the research questions were given operational definitions in Chapter 1. The research questions and theoretical model posit an influence of the students' perception of validation on their integration, academic success, and persistence. As mentioned previously, in this study, integration is measured through the use of a Competent Membership index that incorporates both students' perceptions of belonging to social and intellectual campus communities as well as belief in their ability to be successful in the college environment (Tinto, 1993; Barnett, 2011). Obtaining the data in quantitative form through the use of a survey instrument allowed the use of SPSS software to do data analysis.

\section{Research Design}

This study is based on a correlational quantitative design. According to Frankel, Wallen and Hyun (2012), a correlational design is appropriate for statistical analysis 
that measures the association between variables. The correlational design (Creswell, 2013) is logical given the research questions and the intent to use the study to explore the direction and magnitude of relationships between variables. The design of this study reflects a non-experimental correlational approach (Creswell, 2013), exploring possible relationships between the independent variables, as measured by validation indices, and dependent variables as measured by integration/competent membership, academic success, and persistence.

This study furthers the application of quantitative methods through survey research to explore the relationship between validating experiences and academic success using a cross-sectional quantitative survey. The review of related literature identified that prior research about validation has been primarily completed using qualitative approaches although there has been some recent research using quantitative methods (Barnett, 2011; Hester, 2011; Hurtado, Cuellar, \& Guillermo-Wann, 2011). Survey research in correlational studies is an effective method for examining the relationship between responses to different questions and a measurement or score (Frankel, Wallen \& Hyun, 2012). Survey research can also provide insight from a sample population that may be applicable to a larger population with the caveat that care must be taken to be transparent and to not over-generalize findings. Deploying the survey instrument through an online system offers lower costs and shorter times from data collection to analysis. On the other hand, response rates can be low, necessitating 
either a larger population to meet minimum sampling size or more persistent reminding of participants to complete the survey (Frankel, Wallen \& Hyun, 2012).

The researcher is employed by the study site, which allowed for more convenient access to participants and relevant institutional data. The researcher works indirectly with the Oceania student population at the study site, primarily through the management of academic support programs. There are occasional direct interactions with students which made the use of a survey instrument appropriate for providing a degree of separation between the researcher and subjects and helping to lower researcher bias (Frankel, Wallen \& Hyun, 2012).

\section{Setting}

The research site, Midsized Community College (MCC) is a 2-year, public community college situated in a West coast county with a majority minority populace with non-white residents comprising approximately 60 percent of the total population (US Census, 2010). United States Census data (2010) indicates the county population is more affluent, and more educated than state wide averages. The college operates on a basic aid budget meaning that local property taxes provide adequate revenue to meet annual apportionment obligations to fund enrollment rather than state General Fund monies; however, state categorical program funding is received (Legislative Analyst's Office, 2011). MCC is one college in a three-college district that describes itself as being student-centered, and committed to offering students a comprehensive curriculum 
of basic skills, career and technical programs, and transfer preparation. These match the stated primary missions of the California community college system (California Community College Chancellor's Office, 2018).

The college serves a diverse student population of approximately 9,000 enrolled students in Fall 2017. Table 2 shows the ethnic makeup of MCC and provides context for the Oceania student population and their presence on the campus.

Table 2

Racial/Ethnic Identity of Students at Midsized Community College

\begin{tabular}{llll}
\hline Characteristic & $\begin{array}{l}\text { Survey } \\
\text { Respondents } \\
\text { N (\%) }\end{array}$ & $\begin{array}{l}\text { Oceania } \\
\text { Students at } \\
\text { College N } \\
(\%)\end{array}$ & $\begin{array}{l}\text { Total MCC } \\
\text { Student } \\
\text { Population N } \\
(\%)^{*}\end{array}$ \\
\hline $\begin{array}{l}\text { Ethnicity } \\
\text { African-American }\end{array}$ & $251(2.74 \%)$ \\
American Indian/Alaskan Native & & $9(0.10 \%)$ \\
Asian & & $2,132(23.29 \%)$ \\
Filipino & & $634(6.93 \%)$ \\
Hispanic & & $2,703(29.53 \%)$ \\
Multi-Ethnicity & & $518(5.56 \%)$ \\
Pacific Islander & $65(100 \%)$ & $209(100 \%)$ & $209(2.28 \%)$ \\
Unknown & & $170(1.86 \%)$ \\
White Non-Hispanic & & $2,127(27.61 \%)$ \\
\hline
\end{tabular}


The decision to select MCC as the study site was based on several factors. As an employee of the study site, the researcher had access to relevant data. MCC is a demographically diverse, west coast community college with an Oceania student population that may seem numerically small yet still represents a sizable population. The Oceania population of MCC, approximately 200 representing $2.3 \%$ of the total enrollment at the college, is large enough that investigating their academic outcomes and persistence was perceived as relevant to the institution as well as the local Oceania community. In fact, MCC has established a culturally centered learning community which incorporates Oceania norms and values and offers a certificate program in critical Oceania studies. The age groups and gender make-up of the survey respondents, total Oceania student population and $\mathrm{MCC}$ as a whole, are relatively similar. The research for this study was done entirely with Oceania students so comparisons other student populations at MCC hold little relevance.

\section{Instrument}

This study adapted two existing survey instruments which quantitatively assess validation experiences. The initial instrument was a survey constructed for use in a dissertation by Elisabeth Barnett (2006) who gave written permission to the author to adapt her survey instrument for this study. The survey collected student perceptions of their validation experiences along with demographic data and tested several hypotheses that involved faculty validation, competent membership and their relationships to 
students intent to persist. The initial use of the survey was at an urban community college in Illinois and was validated by experts in the fields of student development and persistence in postsecondary education and tested in order to establish its validity and reliability (Barnett, 2006).

The second survey instrument adapted for this study, the Diverse Learning Environments (DLE) survey, did explore validation coming from other institutional actors through a set of sub-scales. The initial DLE was administered by the Higher Education Research Institute at the University of California at Los Angeles in 2009-10 at three community colleges as well as several four-year institutions (Hurtado, Cuellar, \& Guillermo-Wann, 2011). The DLE used a broader sample of 4,472 students to explore experiences of academic validation in the classroom as well as general interpersonal validation by institutional actors other than faculty (Hurtado, Cuellar, \& Guillermo-Wann, 2011). Data analysis showed the DLE survey validation measures have construct validity and that the DLE survey items represent the two constructs, Faculty and General Interpersonal Validation.

From these two instruments, the researcher constructed a single survey instrument which adapts items from each in order to measure faculty validation, validation by other institutional actors and integration/competent membership. The combined instrument asked participants to respond to 39 Likert-scale items regarding their perceptions of validating experiences by faculty ( 24 items), validation by other 
institutional actors (6 items) and feelings of integration/competent membership (9 items) (Appendix 2). The questions were on a 1 to 7 scale with 1 indicating Strong Disagreement and 7 indicating Strong Agreement (Appendix 1).

Participants were also asked to respond to 9 demographic questions, seen in Table 3, regarding primary language, gender identity, military service, parents' level of education, and participation in special programs.

Table 3

Demographic Control Variables Collected through Survey Instrument

\begin{tabular}{ll}
\hline Variable & Response options \\
\hline Primary Language & Self reported language \\
Gender Identity & Female \\
& Male \\
& Non-binary third gender \\
& Prefer not to state \\
& Prefer to self describe as __ \\
& \\
United States Military Service & Self reported Yes or No \\
Mother's Education & Did not attend high school \\
& Attended but did not finish high \\
& school \\
& Finished high school \\
& Earned an associate's degree \\
& Earned a bachelor's degree
\end{tabular}


Earned a graduate degree

Don't know

Father's Education

Did not attend high school

Attended but did not finish high

school

Finished high school

Earned an associate's degree

Earned a bachelor's degree

Earned a graduate degree

Don't know

Since entering this college have you been a member of the Puente learning community

Self reported Yes or No

Since entering this college have you been a member of Oceania learning community

Since entering this college have you been a member of Umoja learning community

Since entering this college have you played intercollegiate athletics

Self reported Yes or No

Self reported Yes or No

Self reported Yes or No

The data for the dependent variables for this study were collected from the survey instrument and institutional research office of the study site. For this study, academic success was measured by cumulative grade point average (GPA), the number of units attempted, number of units successfully completed, and persistence which was measured by participants' continued enrollment at MCC from Fali 2017 to the Spring 2018 semester. 
Table 4 shows the full list of variables their type, measurement and source of the data.

Table 4

Research Variables and Descriptions

\begin{tabular}{llll}
\hline \multicolumn{1}{c}{ Variable } & Type & Measurement & Source \\
\hline Faculty Validation & Independent & interval, continuous & Survey \\
Validation by Other & Independent & interval, continuous & Survey \\
Primary Language & Independent & nominal, discrete & Survey \\
Military Service & Independent & nominal, & Survey \\
& & dichotomous & \\
Gender İdentity & Independent & nominal, discrete & Survey \\
Special Group or Program & Independent & nominal, & Survey \\
& & dichotomous & \\
Mother's Education & Independent & interval, discrete & Survey \\
Father's Education & Independent & interval, discrete & Survey \\
Age & Independent & interval, discrete & Institutional \\
& & & Research \\
Units Attempted & Dependent & interval, discrete & Institutional \\
& & & Research \\
& & &
\end{tabular}


Units Successfully Dependent interval, discrete Institutional

Completed

Research

Table 4 (continued)

\begin{tabular}{llll}
\hline Variable & Type & Measurement & Source \\
\hline Persistence & Dependent & nominal, & Institutional \\
& & dichotomous & Research \\
Cumulative GPA & Dependent & interval, continuous & Institutional \\
& & & Research \\
Competent Membership & Dependent & interval, continuous & Survey \\
\hline
\end{tabular}

\section{Data Collection and Analysis}

The data collected for the study was from the population of self-identified Oceania students who enrolled at MCC during the Fall 2017 semester. Students were solicited to participate through email and in person based upon their self-identified status as Oceania students. The institutional research office provided the list of email addresses for those enrolled students who had indicated Pacific Islander on their application documents. Courses with high numbers of Oceania students enrolled were also identified for in person requests to participate in the survey research. Those who chose to participate and complete the survey were asked to complete the 39-item, online survey. The study sought responses from 50-100 participants to have an adequate sample size for the data analysis necessary for a correlational study (Fraenkel, Wallen \& Hyun, 2012). To foster interest in completing the survey, an incentive was offered for participating in the study. Eligibility for the incentive, one of five $\$ 25$ gift cards, 
required participants to include their college student ID number in their survey response which would allow the institutional research office to connect respondents with their student record and provide outcome data on units attempted, units completed, cumulative GPA and re-enrollment the following semester.

Descriptive and interpretive analysis of the data collected through the survey and exploring the relationships between the independent variables, Faculty Validation and Validation by Others indices, and dependent variables were done through the analytic tools available through SPSS software. The online survey tool collected the responses into a spreadsheet format that was imported into the statistical software used for analysis. Measures of academic success and persistence were obtained from the institutional research office based upon respondents and the data were carefully integrated into a single data file so that associations of data from survey responses and respondents' academic outcomes and persistence were maintained. Individual identifying data such as student ID numbers were stripped out and correlational analysis, descriptive statistics, and other relevant statistical reports were generated through SPSS

The analysis began with descriptive statistics of all variables prior to conducting correlational analysis. The validation indices were derived from the summed responses on the 1-to-7-point Likert-scale survey items which allowed for a correlational analysis applying a variety of appropriate statistical analyses including t-tests, and cross- 
tabulations, to explore the nature of the relationship between independent and dependent variables: none, positive, negative, linear, or non-linear, and to determine whether or not the relationship is statistically significant and meaningful.

The correlational analysis allowed the researcher to determine whether correlations exist between independent variable indices (Faculty Validation, Validation by Others) and the dependent variables (Competent Membership, GPA, Units Earned and Persistence). Using the other independent variables (Primary Language, Military Service, Gender Identity, Special Group or Program, Mother's Education, Father's Education, Age) as control variables, allowed for quantifying the relationships between the validation indices and integration, academic outcomes and persistence while controlling for the other demographic factors (Wheelan, 2013).

Validity and reliability. Using established survey instruments which have been previously used to measure faculty and general interpersonal validation is one way to ensure that the study is investigating what it claims to be. The items from the Barnett (2006) survey were tested and validated in the creation and use of the instrument. Additional research using the same faculty validation scale (Hester, 2011) further validated the instrument as one that measures student perceptions of validating experiences by faculty. The general interpersonal validation scales from the DLE instrument was also tested and validated. The independent validation of the two instruments should provide adequate support for claiming use of the two scales in a 
combined instrument provided information about validation experiences from both faculty and other institutional actors. Referencing additional studies that used the same or similar scales and methods demonstrates the consistency of results and adds to the credibility of findings. Equally important is accounting for extraneous variables, controlling for them when possible and not overstating claims about results (Fraenkel, Wallen \& Hyun, 2012).

Ethical considerations. Ethical considerations are important in any research. In this study, the participants are community college students 18 , and over therefore not considered a vulnerable population. The researcher received approval from the institutional research office of the study site and the Institutional Review Board (IRB) of San Francisco State University prior to the start of the study. Guidelines provided by the IRB were followed and participants read and acknowledged agreement to a letter of consent outlining the purpose, procedures, and any risks associated with participation in the study.

As an employee at the study site, the researcher has an interest in the outcomes of the research; however, any connection to the participants was minimal. Some of the respondents may have been known to the researcher through the regular course of professional activities at the study site, but the researcher has not had a role as an instructor or academic evaluator for the participants and they were advised that their participation would have no bearing on their grades or status at MCC. 
While completing the survey, participants were reminded that they do not need to respond to questions that make them uncomfortable and could choose not to participate. The survey was administered using NoviSurvey, a software tool for administering surveys online or through email. In the collection of data and analysis of academic outcomes, there is a slight risk of loss of privacy. However, the risk was minimized by limiting access to research data to just the researcher and their faculty advisor. The survey data was password protected and secured using 256-bit SSL encryption. Additionally, any individually identifying information was kept confidential, and no names or identities were used in any published reports of the research. It is the policy of the university that data from the study will be kept for a minimum of three years. Once the study has been concluded and the minimum time for keeping the data has passed, data from the survey and corresponding academic success measures will be deleted.

\section{Summary}

This quantitative study explored the influence of validation from faculty and other institutional actors on integration, academic success and persistence among Oceania students at a suburban, multi-campus community college. Using a survey instrument was the most appropriate design approach for this study. To study the relationships between the independent and dependent variables a quantitative, crosssectional survey of attitudes allowed for the correlational statistical analysis necessary 
to answer the research questions. Studying the perceptions of Oceania students was not an attempt to generalize findings but to add to the current literature on Oceania students' experiences, validation and using quantitative methods to study its relationship to academic outcomes. 


\section{Chapter Four: Report of Findings}

This chapter describes the findings of the research on the influence of validation experiences on the integration, academic outcomes and persistence of Oceania students at Midsized Community College (MCC). The design of this study reflects a conventional correlational approach, exploring possible relationships between the independent and dependent variables. The methodology of this study is a correlational design appropriate for this type of analysis (Frankel, Wallen \& Huyn, 2012). The data collection methods involved adapting a previously validated survey instrument (Barnett, 2006), for collecting the data for this study and receiving student data from the institutional research office. Approximately 200 Oceania students were invited, via email and in person, to complete the survey online. Student demographic data was collected through the survey instrument as well as from institutional sources. The data collected was used to explore the relationships between validation experiences by faculty and other institutional actors, and students' beliefs about their competent membership in the college community, their academic outcomes and persistence. Students of Oceania descent are a little-researched community college population with academic outcomes similar to those of other historically underserved populations. This research extends our understanding of the Oceania community college experience by providing quantitative insights into the influence of validation on integration and outcomes for these students. 


\section{Analysis of Data \\ Descriptive and Frequency Data for Major Variables}

The descriptive analysis completed for this study included frequency and distribution tables to identify any critical flaws or omissions in the data tables. Running frequency and distribution analysis also served to confirm that data was properly imported from the survey and institutional data files into the SPSS data table. The number of respondents to the survey (65) represents a response rate of approximately $31 \%$. The response rate along with the age and gender distributions suggests that the respondents are representative of the larger, MCC Oceania student population.

Control variables. The independent demographic and control variables were operationalized as shown in Table 5. The learning communities, Puente, Umoja, and Oceania, and Student-Athlete, are structured programs which provide multiple techniques for strengthening learning and understanding for the participating students and were included as potentially confounding variables influencing the effect of validation.

Table 5

Demographic and Control Variables and their Operationalization

Variable Operationalization

Age

Chronological age, recoded and grouped

Gender Identity

Recoded Female $=2$, Male $=1$ 
Table 5 (continued)

Demographic and Control Variables and their Operationalization

Variable Operationalization

Mother's Education

Recoded 0-6

Mother's education was recoded based on responses as follows: Don't know $=0$;

Did not attend high school=1; Attended but didn't finish high school=2;

Completed high school=3; Completed some college $=4$; Earned an Associate's degree $=5$ : Earned a Bachelor's degree $=$ 6; Earned a Graduate Degree $=7$.

Father's Education

Recoded 0-6

Father's education was recoded based on responses as follows: Don't know $=0$; Did not attend high school=1; Attended but didn't finish high school=2; Completed high school=3; Completed some college $=4$; Earned an Associate's degree $=5$;

Earned a Bachelor's degree $=6$; Earned a Graduate Degree $=7$.

Puente Member Recoded $0=$ No, $1=$ Yes

Umoja Member

Recoded $0=$ No, $1=$ Yes 
Table 5 (continued)

Demographic and Control Variables and their Operationalization Variable Operationalization

Oceania Member Recoded $0=$ No, $1=$ Yes

Student-Athlete Recoded $0=$ No, $1=$ Yes

In order to demonstrate that the respondents are a good representation of the Oceania and MCC student populations, demographic data showing comparisons of age, and gender identity, are summarized in Tables 6 , and 7 . Some data for the survey respondents and general Oceania student populations were provided by the institutional research office while other current MCC institutional data was retrieved from the California Community College Chancellor's Office Datamart (2018).

Table 6 shows comparisons of the age ranges for the respondents, college Oceania students, and MCC. In order to make accurate comparisons, age was recoded and grouped into ranges. The decision regarding how to group age was based on MCC institutional data reporting within critical planning documents, such as their Educational Master Plan. 
Table 6

Age in Ranges of Respondents, All Oceania Students at Midsized Community College (MCC) and Total MCC Student Population

\begin{tabular}{llll}
\hline Characteristic & $\begin{array}{l}\text { Survey Respondents N } \\
(\%)\end{array}$ & $\begin{array}{l}\text { Oceania Students } \\
\text { at College N }(\%)\end{array}$ & $\begin{array}{l}\text { Total MCC } \\
\text { Student Population } \\
\text { N (\%)* }\end{array}$ \\
\hline Age Range & & & \\
$<20$ & $27(41.54 \%)$ & $80(38.46 \%)$ & $3,121(34.09 \%)$ \\
20 to 24 & $31(47.69 \%)$ & $84(40.86 \%)$ & $3,033(33.14 \%)$ \\
$25 \leq$ & $6(9.23 \%)$ & $44(21.15 \%)$ & $2,999(32.77 \%)$ \\
\hline
\end{tabular}

As Table 6 shows, the percentages within the age ranges are relatively close but Oceania students at $\mathrm{MCC}$ and the survey respondents tend to be younger than the student population of the college as a while with a smaller proportion over the age of 25 (twenty-five).

Although, the survey respondents included a smaller percentage of males than either the Oceania student population or the college as a whole. Gender Identity, shown in Table 7, shows that the distribution of female, male and unknown is reasonably representative of the Oceania population and the MCC student population as a whole. 


\section{Table 7}

Gender Identity of Respondents, All Oceania Students at MCC and Total MCC Student Population

\begin{tabular}{lccc}
\hline Gender Identify & $\begin{array}{l}\text { Survey Respondents N } \\
(\%)\end{array}$ & $\begin{array}{l}\text { Oceania Students } \\
\text { at College N (\%) }\end{array}$ & $\begin{array}{l}\text { Total MCC } \\
\text { Student Population } \\
\text { N (\%)* }\end{array}$ \\
\hline Female & $33(50.8 \%)$ & $97(46.63 \%)$ & $4,416(48.25 \%)$ \\
Male & $29(44.6 \%)$ & $111(53.36 \%)$ & $4,493(49.09 \%)$ \\
Not Given & $3(4.6 \%)$ & - & $244(2.67 \%)$ \\
\hline
\end{tabular}

While institutional data for the total student population only used male or female as gender options, the survey instrument offered greater opportunity for respondents to self-identify beyond the Male/Female binary including the option for an open response to allow for self-identification. Options beyond the heteronormative male/female binary is a validating action allowing students to express their gender self-identity. Being able to research students who identify other than male or female and their validating experiences would have been an informative and important exercise. However, respondents predominantly used the male/female identities with a small number not self-identifying.

Validation indices. Two indices were derived by summing student responses on the survey instrument described in chapter 3. An index for Faculty Validation as well as an index for Validation by Others was derived by summing students' responses to the related items on the survey on a 7-point Likert scale. The complete survey and all items 
are included in Appendix 1. Responses to the two validation measures along with Mean, Median, and Standard Deviation are shown in Table 8 while Figures 2 and 3 show frequency distribution graphs of Faculty Validation and Validation by Others indices, respectively.

Table 8

Validation by Faculty and Validation by Others

\begin{tabular}{|c|c|c|}
\hline & $\begin{array}{l}\text { Faculty Validation } \\
\text { Index }\end{array}$ & $\begin{array}{l}\text { Validation by Others } \\
\text { Index }\end{array}$ \\
\hline Valid & 65 & 65 \\
\hline Missing & - & - \\
\hline Mean & 131.26 & 31.86 \\
\hline Median & 142.00 & 35.00 \\
\hline Std. Deviation & 38.08 & 9.49 \\
\hline Range & 151 & 42 \\
\hline Minimum & 24 & 6 \\
\hline Maximum & 175 & 42 \\
\hline
\end{tabular}


Figure 2 Frequency Distribution of Faculty Validation Index

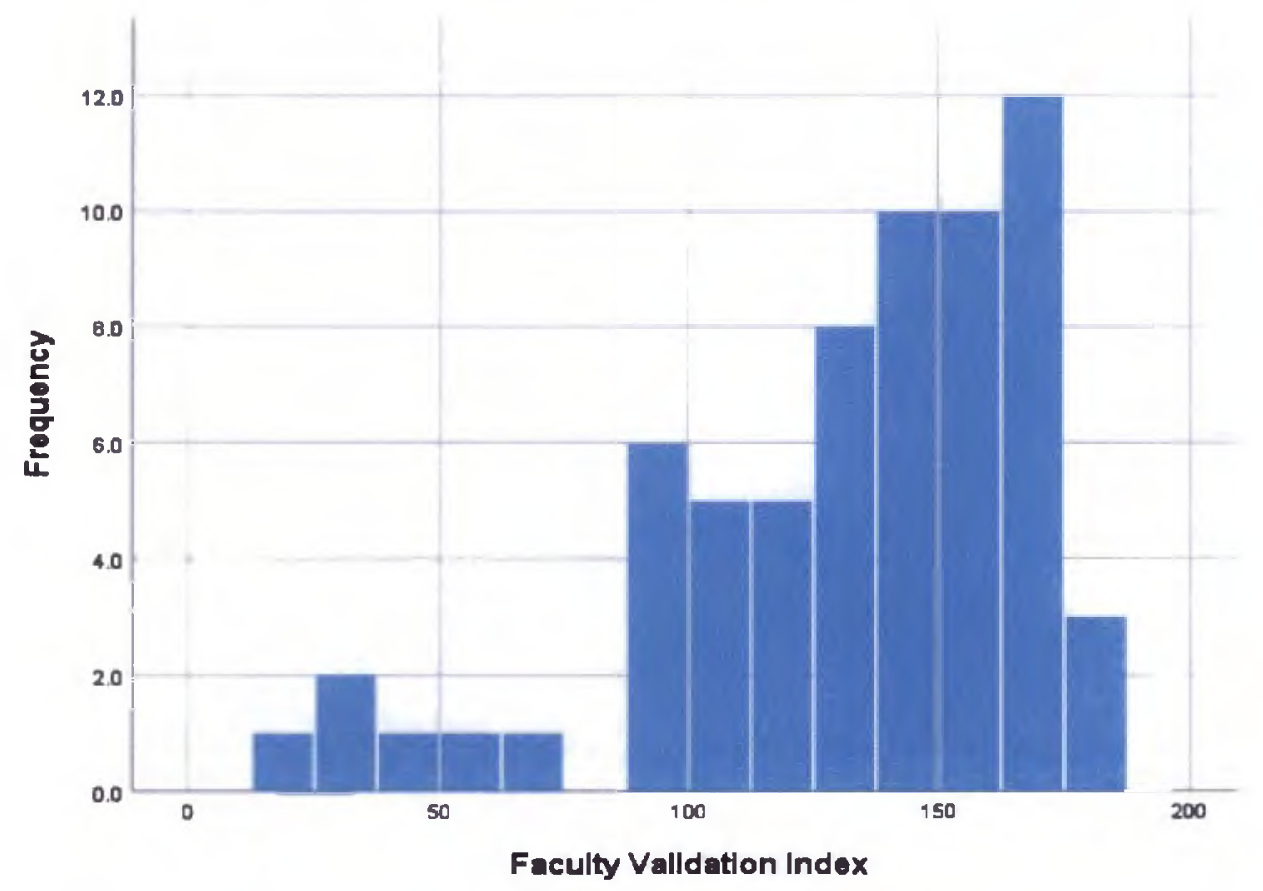

Figure 3 Frequency Distribution of Validation by Others

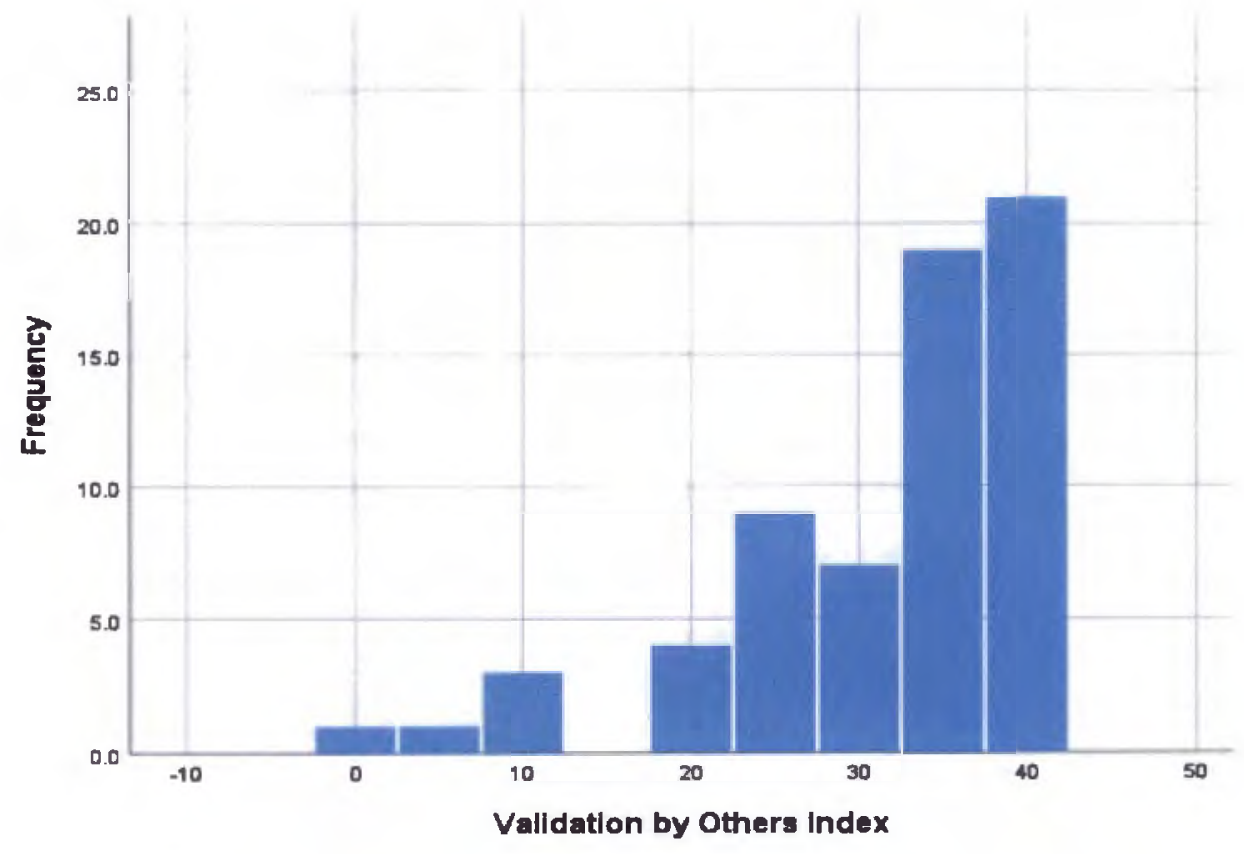


Dependent variables. Table 6 shows the frequency of responses for the interval level dependent variables, along with Mean, Median, and Standard Deviation where appropriate. Competent Membership is a measure of integration and is a sum of the six items related to it on the survey instrument. Figures 4,5 and 6 show the distribution graphs for the interval level dependent variables Competent Membership, Cumulative Grade Point Average and Earned hours respectively. Table 9 and the associated figures provide basic summaries of the features of the dependent variable measures which are explored in more depth when discussing the findings of the guiding research questions.

Table 9

Mean, Median and Standard Deviation of Interval Level Dependent Variables

\begin{tabular}{rlll}
\hline & $\begin{array}{l}\text { Competent } \\
\text { Membership }\end{array}$ & $\begin{array}{l}\text { Cumulative } \\
\text { Grade Point } \\
\text { Average }\end{array}$ & Earned Units \\
\hline Valid & 65 & 64 & 64 \\
Missing & - & 1 & 1 \\
Mean & 32.68 & 2.42 & 31.55 \\
Median & 36.00 & 2.51 & 23.5 \\
Std. Deviation & 9.49 & 0.81 & 26.65 \\
\hline
\end{tabular}


Figure 4 Competent Membership Score Distribution

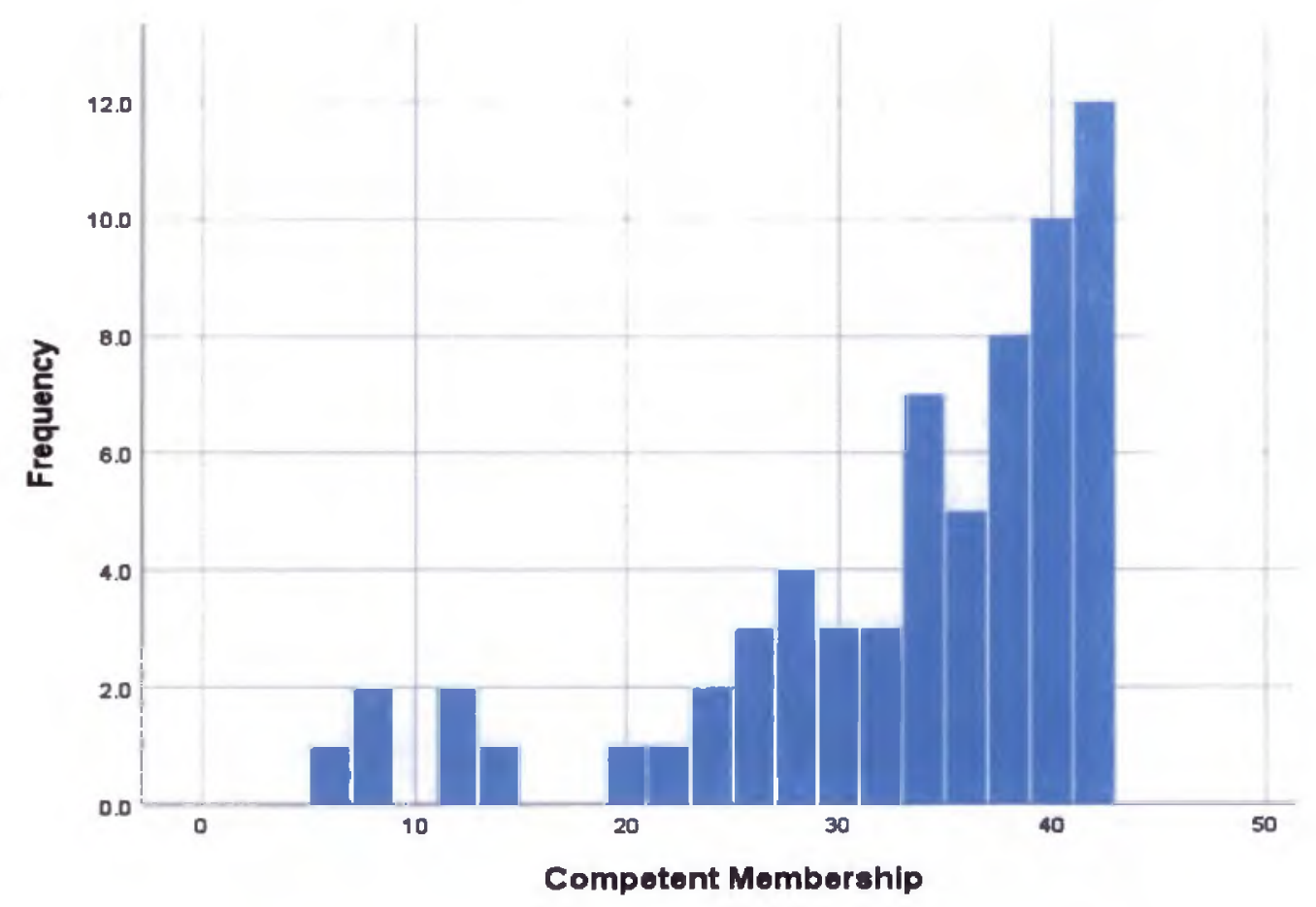

Figure 5 Cumulative Grade Point Average Distribution

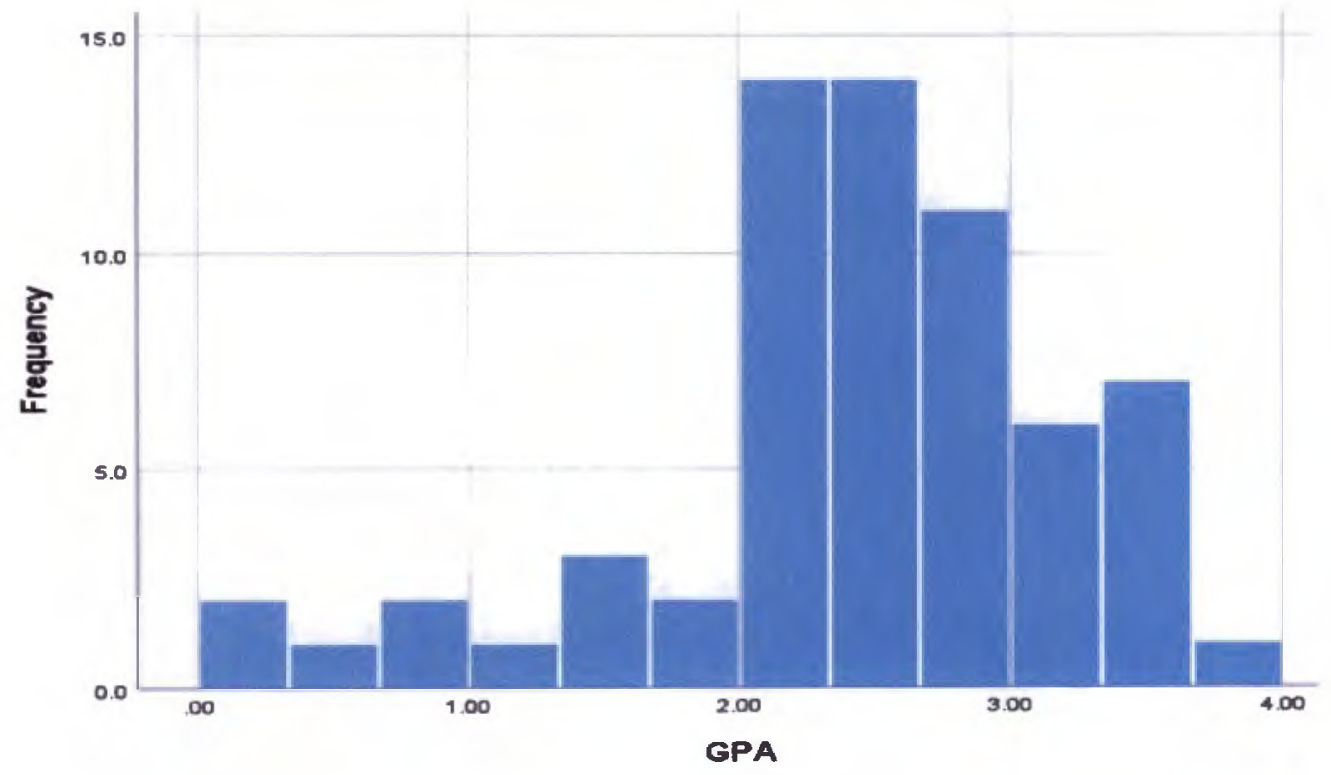


Figure 6 Earned Units Distribution

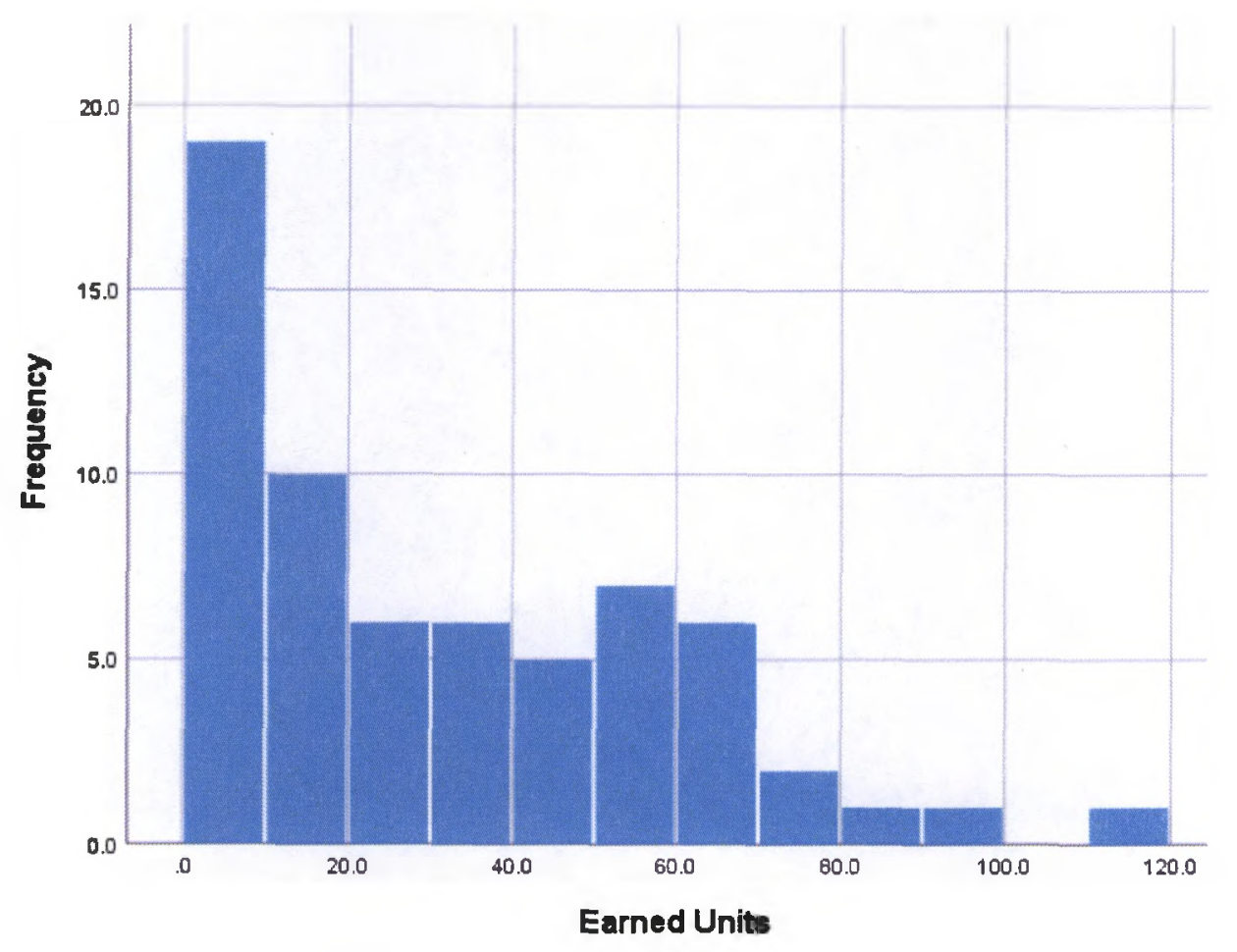

Persistence, a discrete, dichotomous dependent variable, was measured by whether or not students were still enrolled in the spring semester, after beginning in the fall. For this study, the data regarding student persistence was collected after the third week of the semester. Prior to that point, students have the option of dropping or adding courses. Determining students' enrollment status at the beginning of the fourth week of the spring semester was a way of assuring that they had persisted at MCC. The persistence data showed that $56(86.15 \%)$ of the 65 survey respondents were enrolled at the start of the fourth week of the semester, while $9(13.85 \%)$ had not persisted and were not enrolled at that point of the semester. 


\section{Findings Related to Research Questions}

Four research questions guided this study exploring the influence of validation on students' integration, academic outcomes, and persistence. The findings related to each research question are presented in this section. All tests of statistical significance were two-tailed because the direction of relationships between variables was unknown; tests were conducted at a commonly used significance level of .05 (Fraenkel, Wallen \& Hyun, 2012).

Research question 1. Question 1 explored the degree to which Oceania students feel validated by college faculty within the classroom. The results of analysis of Faculty Validation, as shown in Figure 1, shows a substantial range of scores. The Faculty Validation Index descriptives in Table 10 shows that while scores range from 24 to 175 , a median index measure of 142 suggests that students are perceiving high levels of faculty validation.

Table 10

Faculty Validation Index Descriptives (N=65)

\begin{tabular}{llllllc}
\hline & & & & Std. & & \\
& N & Mean & Median & Dev. & Min & Max \\
\hline Faculty Validation & 65 & 131.26 & 142 & 38.08 & 24 & 175 \\
& & & & & & \\
\hline
\end{tabular}

However, differing gender identities and ages are perceiving differences in faculty validation. There were measurable differences in the Faculty Validation Index 
between the male and female students and between the different age range groups as shown in Figures 7 and 8.

Figure 7 Mean Faculty Validation Index by Gender Identity

$$
\begin{aligned}
& 142
\end{aligned}
$$

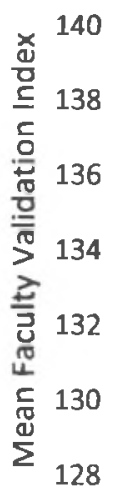

$$
\begin{aligned}
& 126
\end{aligned}
$$

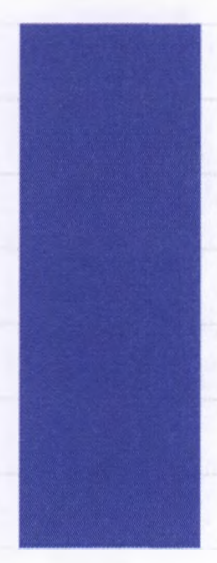

Female

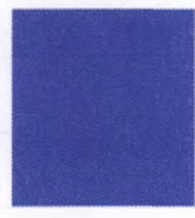

Male

Gender

The mean Faculty Validation Index for male students $(\mathrm{N}=29)$ was 131.3 while the mean score for female students $(\mathrm{N}=33)$ was 140 . There were also differences between age groups with those under 20 years of age perceiving lower levels of faculty validation than those over the age of 20 . 
Figure 8 Mean Faculty Index by Age Range

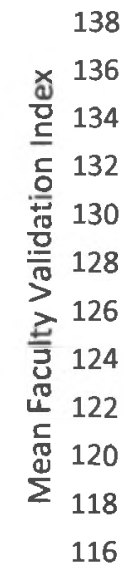

116

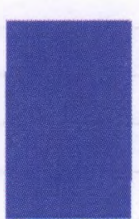

$<20$

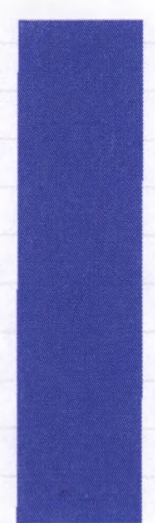

20 to 24 Age Range

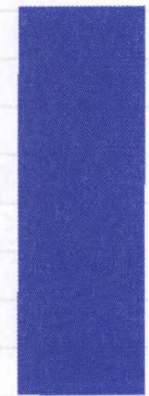

$25 \leq$

The mean Faculty Validation Index for those under 20 years of age was 124.26, lower than that of either the 20 to 24 -year-old group (136.94) or the 25 and older range (132.17).

The intersection of Age and Gender shows that the female respondents tended to be older than the male respondents with a mean age of 21.5 and 19.8 years old respectively. The female respondents also had a much higher mean number of units attempted (59.4) than the male respondents (36.4). The one item related specifically to women in the classroom, "Women are encouraged to contribute to the class discussion", was related to the Faculty Validation Index $(r=.781, p \leq .01)$; however, the three survey items most strongly correlated with the Faculty Validation Index, shown in Table 11, are related to faculty concern for students and in class experiences. 
Table 11

Items Most Strongly Correlated with Faculty Validation Index

\begin{tabular}{|c|c|c|c|c|c|}
\hline & & $\begin{array}{c}\text { My } \\
\text { instructors } \\
\text { seem to } \\
\text { genuinely } \\
\text { care how I } \\
\text { am doing }\end{array}$ & $\begin{array}{c}\text { Most } \\
\text { instructors } \\
\text { are } \\
\text { interested } \\
\text { in what I } \\
\text { have to } \\
\text { offer in } \\
\text { class }\end{array}$ & $\begin{array}{c}\text { I can } \\
\text { generally } \\
\text { express } \\
\text { my } \\
\text { honest } \\
\text { opinions } \\
\text { in my } \\
\text { classes }\end{array}$ & $\begin{array}{c}\text { Faculty } \\
\text { Validation } \\
\text { Index }\end{array}$ \\
\hline \multirow{4}{*}{$\begin{array}{l}\text { Faculty Validation } \\
\text { Index }\end{array}$} & Pearson & $.918^{* t}$ & $.897^{* *}$ & $.865^{* *}$ & 1 \\
\hline & Correlation & & & & \\
\hline & Sig. (2-tailed) & 0.000 & 0.000 & 0.000 & \\
\hline & $\mathrm{N}$ & 61 & 61 & 60 & 65 \\
\hline
\end{tabular}

**. Correlation is significant at the 0.01 level (2-tailed).

While the differences in the Faculty Validation Index between the male and

female students and between the younger and older students did not rise to a level which was statistically significant, it was measurable and meaningful. It is difficult to be more definitive without knowing directionality regarding whether female or older students are perceiving greater faculty validation, therefore, staying longer and attempting more units or if faculty validation may have a longitudinal impact and by persisting students perceive greater levels of faculty validation.

Research question 2. Question 2 examined the degree to which Oceania students feel validated by other institutional actors such as staff, coaches, and counselors. Validation by Others Index is a sum of six survey items. Figure 9 shows the full distribution of Validation by Other Index. The figure shows a strong trend towards 
the high end of the range of perceived validation (mean $=31.86, \mathrm{SD}=9.49$ ) which suggests, overall, respondents feel validated by institutional actors other than faculty. Figure 9 Frequency Distribution of Validation by Others Index

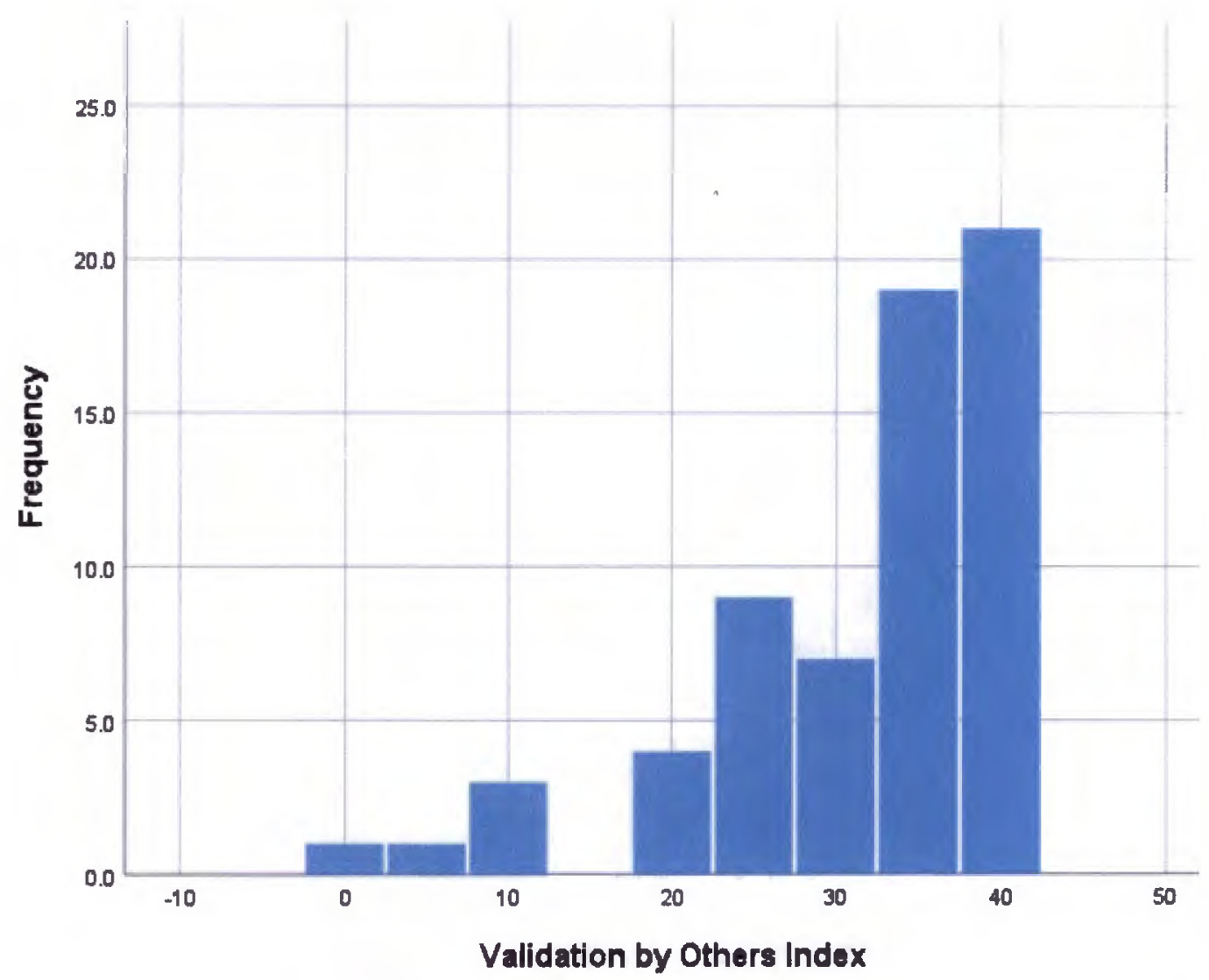

Because of the differences identified in the Faculty Validation Index by Gender Identity and Age Range in Question 1, the same analysis was completed to compare the differences in the Validation by Others Index by those same variables and is shown in Tables 12 and 13 
Table 12

Validation by Others Index by Age Range

\begin{tabular}{rccc}
\hline & \multicolumn{3}{c}{ Age Range } \\
& $<20(27)$ & 20 to $24(31)$ & $25 \leq(6)$ \\
\hline Validation by Others Index & & & \\
Mean & 29.22 & 33.29 & 35.83 \\
Std. Deviation & 10.87 & 8.27 & 7.49 \\
Minimum & 9 & 6 & 22 \\
Maximum & 42 & 42 & 42 \\
\hline
\end{tabular}

Similar to Faculty Validation Index results, older students reported perceiving greater levels of Validation by Others within the academic setting.

Table 13

Validation by Others Index by Gender Identity

Gender Identity

Female (33) Male (29)

Validation by Others Index

Mean $\quad 31.73 \quad 32.21$

Std. Deviation $\quad 10.91 \quad 8.12$

Minimum $\quad 6 \quad 9$

Maximum $\quad 42 \quad 42$

However, as Table 13 shows, male students reported slightly higher levels of Validation by Others than the female students. This is in contrast to the Faculty 
Validation Index, where the female students' index was $6 \%$ higher than male students. While the difference is small, it is noteworthy that the difference in perceptions of faculty validation between the female and male students does not apply to perceptions of non-faculty.

Research question 3. Question 3 examined the relationship between perceived validation experiences and the sense of competent membership (integration) of Oceania students. Using the facuity and other validation indices, the research question explored whether there was a relationship among Oceania community college students' higher levels of validation and a stronger sense of integration in the college as measured by the Competent Membership variable. In other words, among these students, does a sense of integration increase as their level of validation increases?

To explore this research question, correlations between the Faculty Validation Index and the Validation by Others Index were examined in connection to Competent Membership. Bivariate correlations were run using SPSS. Faculty Validation and Validation by Others indices were both found to correlate with students' sense of competent membership at the $p \leq .01$ level of significance. 
Figure 10. Scattergram with Goodness of Fit Line between Faculty Validation Index and Competent Membership $(r=.886, p \leq .01)$

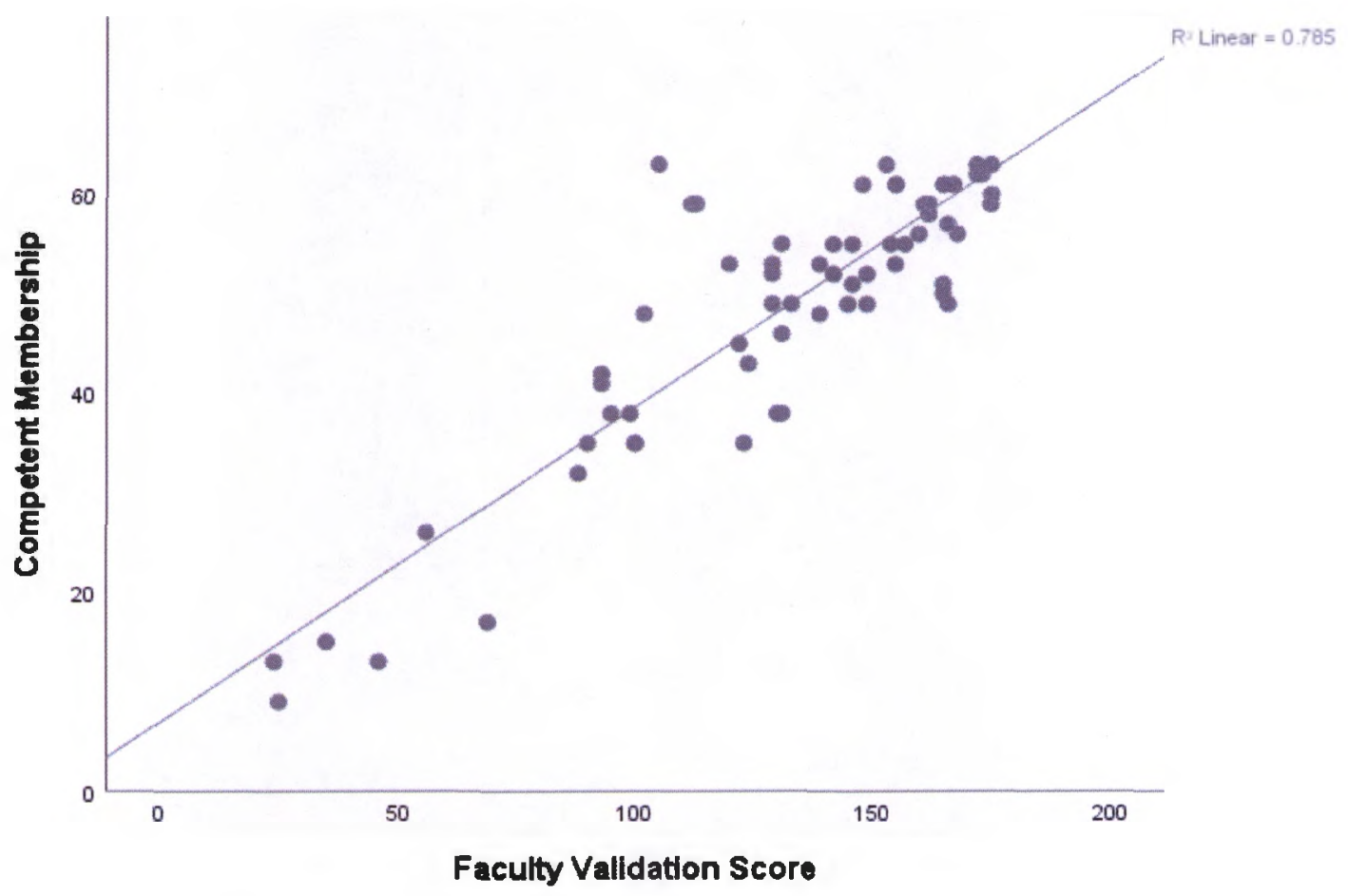

The findings displayed in Figure 10 suggest that higher levels of faculty validation predict greater levels of the students' sense of integration as measured by the Competent Membership scale. Figure 10 shows a similar relationship between Validation by Others and students' Competent Membership. 
Figure 11. Scattergram with Goodness-of-Fit Line Between Validation by Others and Competent Membership ( $r=.593, \mathrm{p} \leq .01)$

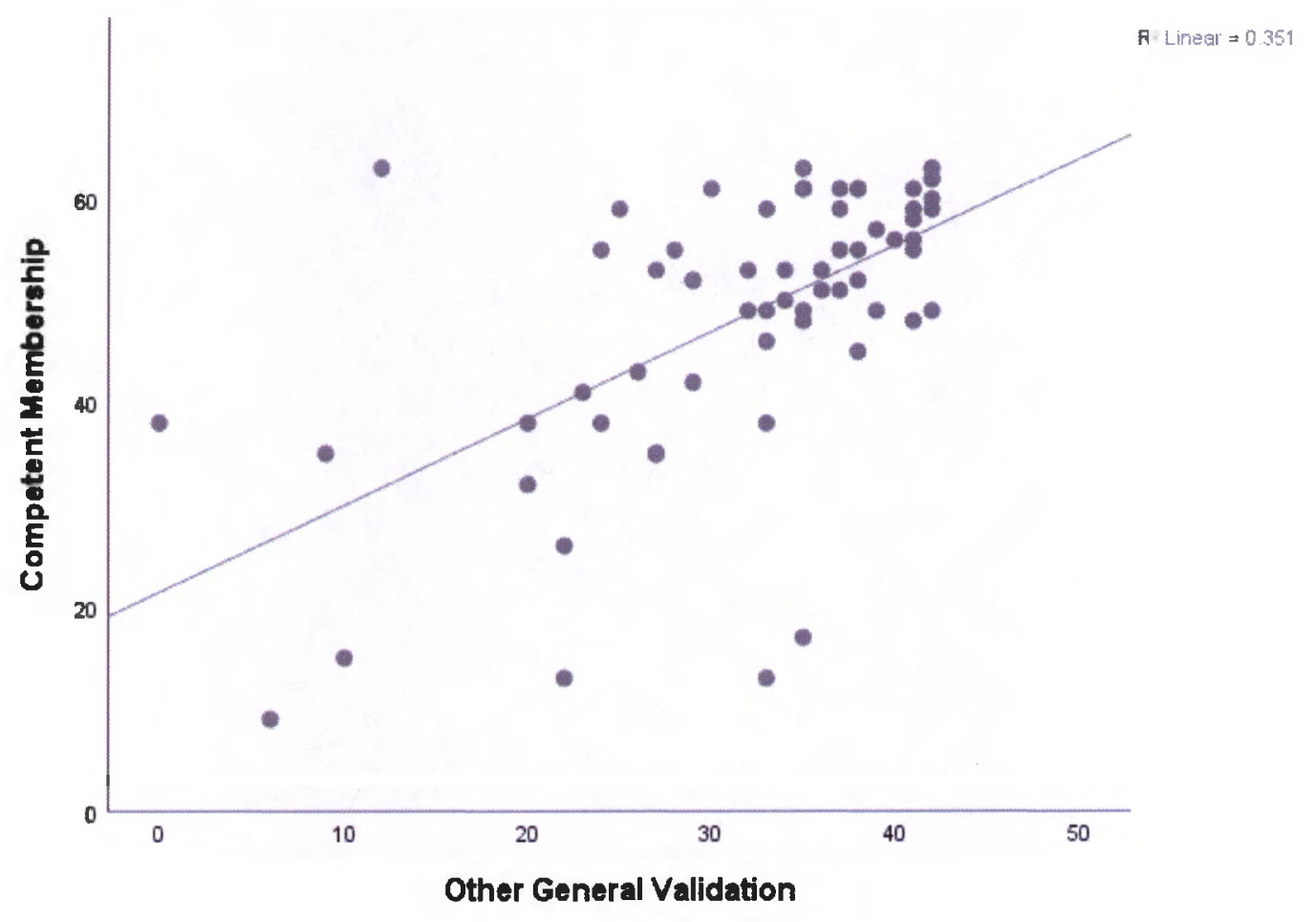

The findings displayed in Figure 11 suggest that validation by institutional actors other than faculty also predicts greater levels of integration for students, although not as strongly as faculty validation. Additional evidence supporting this is seen when looking at the confounding variables related to participation in structured curricular programs like the learning communities. Specifically, participation in the Oceania community was moderately correlated to Validation by Others $(\mathrm{r}=.302, \mathrm{n}=61, \mathrm{p} \leq .05)$. None of the other structured programs, including athletics, showed a significant correlation to validation. 
Research question 4. What is the relationship between perceived validation and the short-term academic outcomes of Oceania students? To explore this research question, the Faculty Validation Index, as weli as Validation by Others Index, were examined for correlation with the measures of academic success. The analysis included whether perceptions of validation predicted success, as measured by GPA and units successfully completed, or persistence. While reporting high levels of validation, neither the Faculty Validation Index nor Validation by Others Index correlated at a statistically significant level to GPA, units successfully completed, or persistence.

However, further analysis of GPA did reveal a noteworthy finding. In order to look beyond just the cumulative GPA, the variable was recoded into three GPA ranges; $1=$ GPA up to $1.99,2=$ GPA 2.00 to 2.99 , and $3=3.00$ and above. A cross-tabulation analysis compared the GPA coded ranges and differences among demographic groups. The results in Table 14 show a significant influence of student participation in the Oceania learning community on student GPA. Students with a cumulative GPA below 2.0 were significantly less likely to be in the learning community (only $12.5 \%$ ), while 41.7 percent of the students with a GPA below 2.0 were not in the learning community. On the other hand, most (75.0\%) of the learning community students were in the 2.0 to 2.99 range. And, for those with GPAs over 3.0, most were also not in the learning community ( 41.7 percent versus 12.5 percent). This suggests a curvilinear relationship 
with learning community students significantly less likely to have either lower than a 2.0 or higher than a 3.0 .

Table 14

Distribution of GPA Coded for Ranges and Oceania Learning Community Participation

\begin{tabular}{|c|c|c|c|c|}
\hline \multirow[b]{2}{*}{ GPA Range } & \multicolumn{4}{|c|}{ Oceania Learning } \\
\hline & & No & Yes & Total \\
\hline \multirow[t]{2}{*}{$\leq 1.99$} & Count & 5 & 6 & 11 \\
\hline & $\%$ within & $41.7 \%$ & $12.5 \%$ & $18.3 \%$ \\
\hline \multirow[t]{2}{*}{$2.00-2.99$} & Count & 2 & 36 & 38 \\
\hline & $\%$ within & $16.7 \%$ & $75.0 \%$ & $63.3 \%$ \\
\hline \multirow[t]{2}{*}{$3.00 \leq$} & Count & 5 & 6 & 11 \\
\hline & $\%$ within & $41.7 \%$ & $12.5 \%$ & $18.3 \%$ \\
\hline \multirow[t]{2}{*}{ Total } & Count & 12 & 48 & 60 \\
\hline & $\%$ within & $100.0 \%$ & $100.0 \%$ & $100.0 \%$ \\
\hline
\end{tabular}

\section{Summary of Findings}

In summary, the analysis of the data collected to address the research questions revealed findings which, while not statistically significant are noteworthy for the four research questions examined in this study. In exploring the extent to which Oceania students at MCC feel validated by faculty and others at the campus, the findings suggest that the students do perceive high levels of validation. There were some differences in 
perceptions of faculty validation by gender with female and older students perceiving higher levels of faculty than male or younger students. Conversely, when it comes to validation by others, male students showed slightly higher validation ratings although older students again felt more validated than the under 20 years old group. While the correlations between age and validation were not statistically significant, the differences between ages and genders are worth noting as a consideration for how faculty and other campus agents interact with various students.

In the analysis of validation and its relationship to integration, these findings suggest a relationship between validation and Oceania students' sense of their own ability to be successful college students. Howver, the relationship is complex, with participation in the Oceania learning community perhaps a confounding variable. Further discussion regarding the implications of this research study and its significance to MCC and the support of Oceania students continues in chapter five. The discussion in chapter five includes recommendations for practice, curricular approaches, dissemination of findings and areas for future research resulting from this study. 
Chapter Five: Discussion and Recommendations

\section{Introduction}

The impetus of this study was to examine the validating experiences of Oceania students at a community college and how perceptions of validation may influence outcomes. The framework for this research was based on Rendón's validation theory and was an extension of prior quantitative approaches to exploring both faculty validation and validation by other institutional actors. The exploration of the experiences of Oceania students at MCC was centered on four research questions:

1. To what degree do Oceania students feel validated by college faculty within the classroom?

2. To what degree do Oceania students feel validated by other institutional actors outside the classroom?

3. What is the relationship between perceived validation experiences and the sense of competent membership/integration of Oceania students?

4. What is the relationship between perceived validation experiences and the short-term academic outcomes of Oceania students?

\section{Interpretation and discussion of findings}

The findings, detailed in chapter 4, were based upon survey responses of Oceania students at a California community college. Data related to Questions 1 and 2 showed that students did feel validated by faculty and other institutional actors although 
there were differences, by gender and age, in the validation ratings. Female students rated faculty validation higher than the male students as did those students who were over the age of 20 .

Identifying how validation may be perceived and acted upon differently by students of different genders was not considered in this research. However, it is an area that may warrant additional exploration. A possible explanation for the differences in faculty validation ratings could be that perceived intensity of validating practices are interpreted differently by male and female students. Many confounding variables could be interacting with validation including the gender or ethnicity of the instructional faculty (Hester, 2011) or that pedagogical approaches were received differently depending upon gender (Zhao, Carini, \& Kuh, 2005).

In addition to the gender differences, the findings brought out differences by age with older students, those 20 and older, rating validating experiences greater than the students under 20 years old. However, the intersection of age and validation is beyond the scope of this research. Similar to gender identity, the differences by age group are an area that may warrant further exploration and raises questions about potential delayed effects that take greater time and exposure to the validating influences of the institution before differences in outcomes can be observed. It is also possible that the older students are developmentally better situated to internalize and benefit from 
validating experiences or that those over 20 years of age who did not feel validated had already departed the college and only those that did feel validated remain.

Delving into the reasons why there were differences in how Oceania male and female students or students younger or older than 20 years old perceived the validating experiences are beyond the scope of this exploratory research. While the differences did not reach a level of statistical significance, research by Wood (2014) and others exploring the perceptions of Black male students, suggest that there are gender differences in perceptions of classroom interactions so it is reasonabie to believe that the differences between Oceania male and female students are real and meaningful In the analysis exploring Question 3 and the relationship between perceived validation experiences and the sense of competent membership/integration of Oceania students, validation is affirming of Oceania students' presence in college and supports a sense of competent membership. A significant connection between validation and students' sense of competent membership seemed to be influenced by students' participation in the Oceania learning community. This is not surprising given the nature of culturally sustaining practices (Paris, 2012) that are used by the faculty and support staff of the learning community. Many of the respondents to the survey were members of the learning community $(n=49)$, and identifying how many of the total Oceania student population have been participants in the learning community is not part of the data collected. It is possible that students from that program felt a greater sense of self- 
efficacy and agency that encouraged their participation in the research resulting in their overrepresentation in the responses.

The additional exploration of GPA data described in chapter 4 did suggest that participation in the Oceania learning community does have an impact on cumulative GPA. While not definitive, it is worth noting, especially since participation in other communities of support measured by the survey did not show similar differences among participants. The $n$ of those other communities was admittedly small, making it difficult to draw any conclusions about differences between communities. Previous research (Pascarella \& Terenzini, 2005) has shown that there are many factors that contribute to academic success and persistence including prior academic preparation and success. These variables were not measured in this research but could be influencing the recorded dependent variables as well.

In exploring the answer to Question 4 and relationship between perceived validation experiences and the short-term academic outcomes of Oceania students, it was anticipated that validation would act to influence academic outcomes like grade point average (GPA), units completed and fall to spring persistence. Prior research had shown a connection between validation and students' intention to persist (Barnett, 2011) and extending the research to look at actual persistence seemed a reasonable next step in the methodology. While the analysis may not have found a statistically significant 
correlation between validation and actual persistence, it could be due to the bias of responses and the number of the survey respondents.

The lack of associational findings between validation and short-term academic outcomes may demonstrate a breakdown in institutional efforts but does not reflect a deficit of the students' efforts, especially for student populations like Oceania, who have been historically marginalized and invalidated. There is a need to rethink student success as being a binary, success or failure. As equitable outcomes become a greater focus for community colleges (CCCCO, 2014; Dowd, 2007), institutions may consider that there are transitional outcomes (Harris III, 2018), such as student integration/competent membership and passing of courses, that need to be reached before equity can be achieved.

\section{Implications and Recommendations for Leadership and Practice}

The purpose of this practitioner-based research and the recommendations that emerge are oriented towards making institutional changes that support the success of all students but especially those student populations that have been historically marginalized and underserved. There is a need to embrace the institutions' responsibility and lead the change necessary for developing the institutional capacity to support Oceania students given their experiences and unique backgrounds. Validation is an approach which shows promise and results from this and prior research (Barnett, 2011; Hester, 2011) suggests that institutions should consider ways to support staff and faculty in becoming validating agents. 
Co-curricular support services and curricular and pedagogical approaches that support Oceania student success should guide how campus leaders operationalize and assess practices like validation. One opportunity to lead the institutional change necessary is through formal state regulations. State Education Code Title 5, Article 2, Section 55724 states "a community college district may designate an amount of time in each fiscal year for employees to conduct staff, student, and instructional improvement activities". While the exact nature of the activities referenced is undefined, one possible approach is professional enhancements demonstrating how validation can be incorporated into the interactions between students and institutional actors inside and outside of the classroom.

Developing individual capacity. The key elements of validation (Rendon, 1994) presented in chapter 3 , include actions by institutional actors which support the students' academic and interpersonal development as well as foster a sense that the students' background and experience are accepted and valuable. Given the importance of non-faculty, institutional actors suggested in this and prior research (Hurtado, et al, 2015: Rendon, 1994, 2002), it becomes incumbent upon those providing student support services to contribute to validating students and supporting their integration as competent members of the campus community. Leaders of community college professional enhancement programs should provide opportunities to build the human capital (Smylie, 1996) of staff. Given the influence of Validation by Others that was 
identified in this research, campus staff should be encouraged and incentivized to engage in professional enhancements that can be applied to improve their interactions with students. Opportunities to learn about transformative practices like validation (Hurtado, et al, 2015 would allow staff members to better support Oceania and other marginalized student groups.

Changes to employment policies would require engaging with collective bargaining units and the institution will need to provide incentives and resources. This is an area where the practitioner/researcher can lead from within their own bargaining unit by sharing insight and knowledge gained through research, such as this, which can be implemented at the local level. A direct result of this research project is the development of professional enhancement modules which incorporate information concerning the lived experiences and cultural values of Oceania students. The goal is to develop a better understanding of how cultural values, such as humility, may manifest in behaviors which can be misunderstood by those with limited understanding of Oceania. Limited understanding can result in responses which negatively impact students' experiences; however, with an understanding of cultural values can come suggestions for strategies that support Oceania students' academic development and success. For example, reminding students that while deference and not speaking up in class may be a culturally appropriate way of demonstrating respect, speaking up in class and asking questions is not a sign of disrespect in American higher education systems. 
Expanding institutional capacity. The findings of this study suggest that one of the ways in which a sense of integration or competent membership is encouraged is through student participation in the MCC Oceania learning community. As Oceania students are navigating the educational environment in pursuit of their goals, the learning community seems to be providing an environment that is validating students and supporting their identity as capable students who belong in college. The results support evidence from previous research (Rocconi, 2010; Tinto \& Russo, 1994; Zhao \& Kuh, 2004) supporting the beneficial outcomes of learning community participation as largely indirect, resulting from increased student engagement.

While the type of highly intrusive and caring environment of a learning community program does not scale easily, it is possible to share the model with other community colleges that have large enough Oceania populations to support a similar learning community at their institution. Sharing information and results from this and other studies to help cultivate learning communities at multiple community colleges can improve cultural understanding and competence of Oceania at multiple locations. This presents an opportunity for local leaders to create a network of mutually supportive and beneficiai communities to support Oceania community college students. Sharing knowledge and expanding capacity across locations could lead to broader gains in academic outcomes across the community college system for Oceania students. Establishing Oceania based learning communities also has symbolic implications as it 
signals that the needs of Oceania are on the same level as other marginalized student populations. It also signals to the broader community that the college recognizes the unique challenges faced by Oceania students and its willingness to make the success of those students a priority.

Curricular and Pedagogical Approaches. Faculty play a critical role in supporting student success. Their interactions with students can validate them as competent and capable members of the college community (Hester, 2011; Rendón, $1994,2002)$. With the growth of the Oceania population in the classroom, it is important for faculty to consider their teaching methods and assumptions about student learning. Maintaining high expectations while developing the cultural competence to better facilitate success for Oceania and other historically underserved students requires an ongoing process of training and critical self-reflection. A regular program of professional and pedagogical development can inform faculty practice in creating inclusive, validating learning environments which may lead to improved academic outcomes and degree attainment for all students.

Campus leaders can facilitate on-going professional and pedagogical enhancements through policy and developing a campus culture that values faculty who participate in activities which would enhance their teaching. As an example, the flexible hours policy of MCC requires that full-time, tenure or tenure track faculty complete 25 hours of activities each year, oriented towards professional improvement, pursuant to 
Title 5, Article 2, Section 55724. The college organizes 6 days each academic year to provide opportunities for faculty to satisfy their obligations; however, with less than $50 \%$ of faculty at MCC being identified as full-time, tenure or tenure track (California Community Colleges Chancellor's Office, 2017-c) it leaves a large number of part-time, instructional faculty without meaningful motivation to enhance their professional skills. A policy amendment which similarly requires and properly incentivizes an annual minimum number of hours of professional enhancement or training directly related to instructional and pedagogical improvement for part-time faculty could significantly impact classroom practices. However, while Smylie (1996) argues for the importance of building the capacity of teachers and the importance in education reform of ongoing professional enhancement he also cautions that prescriptive policies that focus solely on directing behaviors, and building mechanisms for accountability rarely incentivize educators to improve their craft.

Institutions would be better served if capacity building (Fowler, 2014) was included in plans for developing standards and assessments for staff and faculty. That would mean offering professional development opportunities which support improved practice, and teaching strategies and pedagogy that incorporates cultural competency. Student support practitioners, as well as classroom instructors, would be able to advance their subject knowledge as well as knowledge of teaching and learning and apply both 
to further the academic development of Oceania as well as other historically underserved student populations.

\section{Recommendations for Future Research}

The research conducted for this study showed some promising findings; however, additional research is needed to further the evidence of the usefulness of validation as a construct and as a practice for supporting Oceania students' success.

Findings suggest that validation by faculty and non-faculty did have an impact on competent membership/integration of students. The use of the quantitative model for this study was heipful in furthering understanding validation as a concept; however, measuring a complex construct like validation for Oceania students would benefit from additional research using qualitative methods of study. As Nora, Urick and Quijada Cerecer (2011) noted in their discussion of extending validation, it is based on individual perceptions of experiences. Thus, while using a survey can be insightful, it can fail to recognize the experiences of individual participants. Including Oceania students' voices would clarify the validating agents' role and the interactive process between Oceania students and the faculty and other institutional actors of the college.

Another area of further research is related to the influence that participation in the learning community had on students' sense of competent membership/integration. Additional research is necessary to determine what aspects of the learning community are associated with validation, how those interactions influence students' academic 
success and persistence, and to what degree. Examining the influence of the learning community would be helpful to identify specific practices which could be shared and possibly adopted more broadly.

There is also a missing element that warrants additional research which is the experience of those students who did not persist and return in the spring semester. Without additional research that explores the experiences of those students who do depart the college, a significant gap in research will exist. Although more than $85 \%$ of the survey respondents persisted in the spring semester, that still leaves a significant percentage who did not re-enroll. The possible causes for not persisting are too numerous to speculate but some may have been a result of institutional actions or inactions which either pushed the student our or incentivized their departure.

One of the limitations of this study was the relatively brief time frame studied. A longitudinal study that followed Oceania students over a longer period of time would help to reveal if there may be delayed effects or sustained benefits of validation over time. Taking a longer view could also reveal whether validation translates into improved rates of students' end goal achievement, whether that is measured by workforce entry, transfer, or degree attainment.

An additional limitation of this approach which suggests a need for further research is the omission voice of students. As a quantitative study, this instrument does not include student voices. A deeper investigation that incorporates a qualitative 
exploration of processes or specific interactions which are perceived as validating would add significantly to strengthen this area of research.

\section{Disseminating Findings}

As a practitioner/researcher, it is easy to understand the impulse to favor the practitioner aspect and disregard the researcher. However, with so little published research on the experiences of Oceania students in American higher education systems, it is more important than ever to embrace the researcher role and share this study to allow other practitioners and researchers to use, extend, and build upon it so that Oceania and other similarly situated students may benefit.

Opportunities for disseminating this study locally and more broadly are many and varied. On the local level, because this research was conducted at a single institution, there are opportunities to share the findings with relevant campus committees, especially those tasked with issues of equity and student success. There are also opportunities to develop additional workshop activities to enhance praxis of faculty and staff. Furthermore, it is important to share the study with the participants, so engaging with the Oceania students themselves through presentations to student groups and making the study publicly available are key outlets.

Sharing the study beyond the local level and engaging with other Oceania scholars necessitates the use of additional outlets. The two most prominent are publishing in research journals and presenting at relevant conferences. Due to the short 
time period covered in this study, additional data may need to be collected in order for it to be considered for publication but journals that focus on community college research and practice or those that have a focus on Oceania would be the most likely to find the information relevant and worthy of publication. While publishing research can take some time, conferences are another channel for disseminating research which may be more readily accessible. This research connects to several areas which would be appropriate for conference presentation including methodology, student success, learning communities, and Oceania. Regional and topical conferences may find the information from this study of interest and are potential outlets for sharing.

Whether practitioner, researcher or both, the information from this study shines a light on the little researched Oceania community college student population. Given the anticipated growth of this student population and the demonstrated need to support their success, disseminating the information from this study and engaging in critical dialogue about its implications and applicability is an important step towards a better understanding not only Oceania but of practices and pedagogy which can support success for all students.

\section{Conclusion}

Current research does not adequately explain the educational experiences of Oceania students. While their academic outcomes are similar, the social and academic experiences of Oceania students are different from those of other historically 
underrepresented and underserved student populations due to their differing history of colonization and immigration. As community colleges continue to play a significant role in the education of historically underrepresented and marginalized populations, it is imperative that they leverage resources in support of equity goals. Rendón's (1994) theory suggests that validation of students' experiences and backgrounds is critical to their personal and academic development.

This study examined the relationship of student perceptions of validating actions of faculty and other institutional actors and short-term academic outcomes, persistence, and sense of competent membership/integration. Findings suggested that validation has a significant influence on students' sense of competent membership and, while there seemed to be some meaningful and noteworthy differences in grade point average, that appears to be largely a product of participation in an Oceania learning community. The limitations of the study mean that findings may be site dependent and are likely not generalizable.

The results of this study provide MCC college leaders with information about the influence of validation on academic success and persistence for Oceania students. These results have the potential to inform college leaders regarding the Oceania student population, existing challenges, and supports that influence their success. The implications of the research suggest that the institution create professional development activities for staff and faculty which emphasize the importance of cultural competence 
and culturally sustaining pedagogy (Ladson-Billings, 1995, 2014; Gay, 2013). Engaging in information sharing and professional development could lead to further opportunities to analyze, and collaborate to create institutional changes (Fullan, 2001) that support success for Oceania and transform institutions to better support all students. 


\section{References}

Astin, A. W. (1984). Student involvement: A developmental theory for higher education. Journal of College Student Development, 40(5), 518-529. Retrieved from https://www.researchgate.net/publication/220017441.

Aud, S., Fox, M., and Kewal Ramani, A. (2010). Status and Trends in the Education of Racial and Ethnic Groups (NCES 2010-015). U.S. Department of Education, National Center for Education Statistics. Washington, DC: U.S. Government Printing Office.

Auguste, B., Hancock, B., \& Laboissiere, M. (2009). The economic impact of the achievement gap in America's schools. New York, NY: McKinsey \& Company.

Bailey, T. R., Jaggars, S. S., \& Jenkins, D. (2015). Redesigning America's community colleges: A clearer path to student success. Cambridge, Ma: Harvard University Press.

Barnett, Elisabeth A., (2011). Validation experiences and persistence among community college students. The Review of Higher Education 34(2), 193-230.

Baum, S., Ma, J., \& Payea, K. (2013). Education pays 2013. The College Board.

Beachboard, M., Beachboard, J., Wenling, L., \& Adkison, S. (2011). Cohorts and Relatedness : Self-Determination Theory as an Explanation of How Learning Communities Affect Educational Outcomes. Research, 52(8), 853-874.

Berger, J. B., \& Milem, J. F. (1999). The role of student involvement and perceptions of integration in a causal model of student persistence. Research in Higher Education, 40(6), 641-664. Retrieved from http://www.jstor.org/stable/40196897

Bers, T. \& Younger, D. (2014). The first-year experience in community colleges. New Directions for Institutional Research 160, 77-93. doi: 10.1002/ir.20062

Borrero, N., Yeh, C., Tito, P. \& Luavasa, M. (2010). Alone and in between cultural and academic worlds: Voices of Samoan students. University of San Francisco School of Education Faculty Research Paper 2, 47-55.

Bragg, D. D. (2001). Community college access, mission, and outcomes: Considering intriguing intersections and challenges. Peabody Journal of Education, 76(1), 93-116. Retrieved from http://www.jstor.org/stable/1493007

Braxton, J. M. (Ed.). (2000). Reworking the student departure puzzle. Vanderbilt University Press. 
Braxton, J. M., Sullivan, A. S., \& Johnson, R. M. (1997). Appraising Tinto's theory of college student departure. In J. C. Smart (Ed.), Higher education: A handbook of theory and research (Vol. 12, pp. 107-164). New York: Agathon Press.

Bray, M. (1993). Education and the vestiges of colonialism: Self-determination, neocolonialism and dependency in the South Pacific. Comparative Education 29(3), 333-348.

Burnett, G. (2002). Technologies and discourses of colonialism in education in the Republic of Kiribati. Journal of Educational studies, 24(2), 10-23.

California Community Colleges Chancellor's Office (2014). http://extranet.cccco.edu/Divisions/StudentServices/StudentEquity.aspx.

California Community Colleges Chancellor's Office (2016). Percentage of degree, certificate and/or transfer-seeking students starting first time in 2008-09 tracked for six years through 2013-14 who completed a degree, certificate or transferrelated outcomes. Retrieved from http://scorecard.cccco.edu/scorecardrates.aspx?CollegeID $=000$ thome

California Community Colleges Chancellor's Office (2017-a). Annual student count report. Retrieved from http://datamart.cccco.edu/Students/Student Term_Annual Count.aspx

California Community Colleges Chancellor's Office (2017-b). Retrieved from http://datamart.cccco.edu/DataMartError.Aspx?aspxerrorpath=/Students/DataM art.aspx.

California Community Colleges Chancellor's Office (2017-c). Retrieved from http://datamart.cccco.edu/Faculty-Staff/Staff_Demo.aspx.

Campaign for College Opportunity (2015). The state of higher education in California: Asian Americans, Native Hawaiians, Pacific Islanders. Retrieved from http://collegecampaign.org/wp-content/uploads/2015/09/2015-State-of-HigherEducation AANHPI2.pdf.

Carnevale, A., Rose, S., \& Cheah, B. (2011). The college payoff: Education, occupations, lifetime earnings. Washington, DC: Georgetown University Center on Education and the Workforce.

Choi, D. K. (2010). A unique racial experience: Examining Asian American and Pacific Islander college students and campus climate (Doctoral dissertation).

Clifford, J. (1994). Diasporas. Cultural Anthropology, 9(3), 302-338. 
College of San Mateo (2014). College of San Mateo student equity plan. Retrieved from http://collegeofsanmateo.edu/prie/docs/CollegeofSanMateoStudentEquityPlanFi nal 12-17-14version.pdf.

College of San Mateo (2013). Self-evaluation report of educational quality and institutional effectiveness in support of reaffirmation of accreditation. Retrieved from http://collegeofsanmateo.edu/2013selfevaluation/docs/final report/CSMSelfEva IVol1 8-21-13FINAL.pdf.

Creswell, J. W. (2013). Research design: Qualitative, quantitative, and mixed methods approaches. Thousand Oaks, Ca: Sage Publications.

Crisp, G., Taggart, A., \& Nora, A. (2015). Undergraduate Latina/o students: A systematic review of research identifying factors contributing to academic success outcomes. Review of Educational Research 85(2), 249-274.

Cunningham, A. (2006). The Broader Societal Benefits of Higher Education. Solutions for Our Future Project, (202).

Dee, T. S., \& Penner, E. K. (2016). The causal effects of cultural relevance: Evidence from an ethnic studies curriculum. American Educational Research Journal, 54(1), 127-166. http://doi.org/10.3102/0002831216677002

Dowd, A. (2007). Community colleges as gateways and gatekeepers: Moving beyond the access" saga" toward outcome equity. Harvard Educational Review, 77(4), 407-419.

Engle, J. \& Tinto, V. (2008). Moving beyond access: College success for low-income, first-generation students. Washington, D.C.: The Pell Institute.

Eves, R. (1996). Colonialism, corporeality and character: Methodist missions and the refashioning of bodies in the Pacific. History and Anthropology, 10(1), 85-138.

Fowler, F.C. (2014). Policy studies for educational leaders: An introduction. Allyn \& Bacon/Pearson.

Frankel, J. R., Wallen, N. E. \& Hyun, H. H. (2012). How to design and evaluate research in education. New York, NY: McGraw-Hill.

Fullan, M. (2014). Leading in a culture of change. San Francisco: Jossey-Bass.

Gay, G. (2013). Teaching to and through cultural diversity. Curriculum Inquiry, 43(1), 48-70. http://doi.org/10.1111/curi.12002 
Gershon, I. (2007). Viewing diasporas from the Pacific: What Pacific ethnographies offer Pacific diaspora studies. The Contemporary Pacific, 19(2), 474-502.

Goldrick-Rab, S. (2010). Challenges and opportunities for improving community college student success. Review of Educational Research 80(3), 437-469.

Gorski, P. C. (2008). Peddling poverty for profit: Elements of oppression in Ruby Payne's framework. Equity and Excellence in Education, 41(1), 130-148. http://doi.org/10.1080/10665680701761854

Guifrida, D., (2006). Toward a cultural advancement of Tinto's theory. The Review of Higher Education 29(4), 451-472.

Hagedorn, L. S. (2005). How to define retention: A new look at an old problem. In A. Seidman (Ed.), College student retention (pp. 89-105). Westport: Praeger Publishers.

Hall, L. K. (2015). Which of these things is not like the other: Hawaiians and other Pacific Islanders are not Asian Americans, and all Pacific Islanders are not Hawaiian. American Quarterly, 67(3), 727-747. http://doi.org/10.1353/aq.2015.0050

Harris III, F., (2018, March). Training presented at College of San Mateo.

Hau'Ofa, E. (1993). Our sea of islands. A new Oceania: Rediscovering our sea of islands, 2-16.

Heine, H. C. (2002). Culturally Responsive Schools for Micronesian Immigrant Students. PREL Briefing Paper.

Hester, D. (2011). Influences of faculty validation on community college STEM students ' persistence and success (Doctoral dissertation). Retrieved from ProQuest Dissertations and Theses database. (UMI Number: 3472527).

Hezel, F. X., \& Samuel, E. (2006, December). Micronesians abroad. Micronesian Counselor, 64. Retrieved from http://micsem.org/pubs/counselor/frames/microsabroadfr.htm

Hurtado, S., Alvarado, A., \& Guillermo-Wann, C. (2015). Creating inclusive environments: The mediating effect of faculty and staff validation on the relationship of discrimination/bias to students' sense of belonging. Journal Committed to Social Change on Race and Ethnicity 1(1), 60-81. 
Hurtado, S., Cuellar, M., \& Guillermo-Wann, C. (2011). Quantitative measures of students' sense of validation: Advancing the study of diverse learning environments. Enrollment Management Journal, 5(2), 53-71.

Inkelas, K. K., Szelenyi, I., Soldner, M., \& Brower, A. M. (2007). National Study of Living-Learning Programs: Report of Findings. College Park, MD.

Kahaleole Hall, L. (2008). Strategies of erasure: U.S. colonialism and native Hawaiian feminism. American Quarterly 60(2), 273-280.

Karen, D., \& Dougherty, K. J. (2005). Necessary but not sufficient: Higher education as a strategy of social mobility. Higher education and the color line: College access, racial equality, and social change, 33-57.

Kirsch, I., Braun, H., Yamamoto, K., \& Sum, A. (2007). America's perfect storm: Three forces changing our nation's future. Princeton: Educational Testing Service.

Kuh, G. D., \& Love, P. G. (2000). A cultural perspective on student departure. In J. M. Braxton (Ed.), Reworking the student departure puzzle (pp. 196-212). Nashville, TN: Vanderbilt University Press.,

Kupferman, D.W., (2009). Lutlut in a strange land: Kosraean immigrant perceptions of schooling in Hawai'i. Micronesian Educator, 13(1), 19-34.

Ladson-Billings, G. (1995). Toward a Theory of Culturally Relevant Pedagogy. American Educational Research Journal, 32(3), 465-491. http://doi.org/10.3102/00028312032003465

Ladson-Billings, G. L. (2014). Culturally Relevant Pedagogy 2.0 : a.k.a. the remix. Harvard Education Review, 84(1), 74-85.

Lee, S., \& Kumashiro, K. (2005). A report on the status of Asian Americans and Pacific Islanders in education; Beyond the model minority stereotype. National Education Association.

Lingam, G. I., Burnett, G., Lilo, J. F., \& Lingam, N. (2014). Curriculum reform in Solomon Islands: a shift from Eurocentrism to Solcentrism in curriculum making. The Asia-Pacific Education Researcher, 23(3), 345-353.

Liu, E., \& Liu, R. (1999). An application of Tinto's model at a commuter campus. Education 119(3), 537-541. 
Lui, J. (2013). Grades of the not so modeled: Asian American and Pacific Islander transfer students at Middle University. Community College Journal of Research and Practice, 37(3), 205-215.

Makuakane-Drechsel, \& Hagedorn. (2000). Correlates of retention among Asian Pacific Americans in community colleges: The case for Hawaiian students. Community College Journal of Research and Practice, 24(February), 639-655. http://doi.org/10.1080/10668920050140800

Martinsen, N. (2017). Supporting Pacific Islander student success in higher education through culturally sustaining leadership (Doctoral dissertation). Retrieved from https://diva.sfsu.edu/users/eddsfsu/courses/dissertations

McFarland, J., Hussar, B., de Brey, C., Snyder, T., Wang, X., Wilkinson-Flicker, S., Gebrekristos, S., Zhang, J., Rathbun, A., Barmer, A., Bullock Mann, F., and Hinz, S. (2017). The Condition of Education 2017 (NCES 2017144). U.S. Department of Education. Washington, DC: National Center for Education Statistics. Retrieved from https://nces.ed.gov/pubsearch/pubsinfo.asp?pubid=2017144.

Milner, R. H. (2007). Race, culture, and researcher positionality: Working through dangers seen, unseen and unforeseen. Educational Researcher 36(7), 388-400.

Moore, C., \& Shulock, N. (2010). Divided we fail: Improving completion and closing racial gaps in Callfornia's community colleges. Sacramento, Ca: Institute for Higher Education Leadership \& Policy.

Morton, H., (1998). Creating their own culture: Diasporic Tongans. The Contemporary Pacific 10(1), 1-30.

Museus, S.D. (2009). A critical analysis of the exclusion of Asian Americans from higher education research and discourse. In L. Zhan (Ed.), Asian American voices: Engaging, empowering, enabling (pp. 59-76). New York: NLN Press.

Museus, S. D. (2014). The culturally engaging campus environments (CECE) model: A new theory of success among racially diverse college student populations. In Higher Education: Handbook of Theory and Research 29, 189-227. Retrieved from

https://pdfs.semanticscholar.org/5d75/80a0477433d5bc3784d2684bb76c258031 d4.pdf

Museus, S.D., \& Kiang, P. (2009). Deconstructing the model minority myth and how it contributes to the invisible minority reality in higher education research. New Directions for Institutional Research 142(7), 5-15. 
Museus, S. D., Mueller, M. K., \& Aquino, K. (2013). Engaging Asian American and Pacific Islander culture and identity in graduate education. The misrepresented minority: New insights on Asian Americans and Pacific Islanders, and their implications for higher education, 106-123.

Museus, S. D., \& Neville, K. M. (2012). Delineating the ways that key institutional agents provide racial minority students with access to social capital in college. Journal of College Student Development. 53(3), 436-452. Retrieved from http://search.proquest.com/docview/1019049706?accountid=13802

Museus, S. D., Nichols, A. H., \& Lambert, A. D. (2008). Racial differences in the effects of campus racial climate on degree completion: A structural equation model. The Review of Higher Education, 32(1), 107-134.

Museus, S. D., Palmer, R. T., Davis, R. J., \& Maramba, D. (2011). Racial and ethnic minority student success in STEM education: ASHE higher education report. John Wiley \& Sons.

Museus, S. D., \& Quaye, S. J. (2009). Toward an intercultural perspective of racial and ethnic minority college student persistence. The Review of Higher Education, 33(1), 67-94. http://doi.org/10.1353/rhe.0.0107

National Center for Education Statistics, 2015. Percentage of persons 25 to 29 years old with an associate's or higher degree, by sex and race/ethnicity: 1992 through 2015. Retrieved from https://nces.ed.gov/fastfacts/display.asp?id=27

Neumark, D., Johnson, H., \& Mejia, M. C. (2013). Future skill shortages in the US economy? Economics of Education Review, 32, 151-167.

Nora, A., Urick, A., \& Quijada Cerecer, P. (2011). Validating students: a conceptualization and overview of its impact on student experiences and outcomes. Enrollment Management Journal 5(2), 34-52.

Pang, V. O. (2007). Asian Pacific American cultural capital: Understanding diverse parents and students. Narrowing the Achievement Gap, 49-64.

Pang, V. O., Han, P. P., \& Pang, J. M. (2011). Asian American and Pacific Islander students : Equity and the achievement gap. Educational Researcher, 40(8), 378389. Retrieved from http://www.jstor.org/stable/41302978

Paris, D. (2012). Culturally sustaining pedagogy: A needed change in stance, terminology, and practice. Educational Researcher, 41(3), 93-97. http://doi.org/10.3102/0013189X12441244 
Pascarella, E. T., \& Terenzini, P. T. (2005). How college affects students: A third decade of research (Vol. 2). San Francisco: Jossey-Bass.

Perna, L. W. (2005). The benefits of higher education: Sex, racial/ethnic, and socioeconomic group differences. The Review of Higher Education, 29 (1), 2352. Retrieved from http://dx.doi.org/10.1353/rhe.2005.0073

Poon, O., Squire, D., Kodama, C., Byrd, A., Chan, J., Manzano, L., Furr, S. \& Bishundat, D. (2016). A critical review of the Model Minority Myth in selected literature on Asian Americans and Pacific Islanders in higher education. Review of Educational Research 86(2), 469-502.

Rendón, L. I. (1994). Validating culturally diverse students: Toward a new model of learning and student development. Innovative Higher Education 19(1), 33-51.

Rendón, L. I. (2002). Community college Puente: A validating model of education. Educational Policy, 16(4), 642-667. doi: 10.1007/BF01191156.

Rendón, L. I., \& Jalomo, R. E., (1995). Validating student experience and promoting progress, performance and persistence through assessment.

Rendón, L. I., Jalomo, R. E., \& Nora, A. (2000). Theoretical considerations in the study of minority student retention in higher education. In J. Braxton (Ed.), Reworking the student departure puzzle (pp. 127-156).

Rendón - Linares, L. I. R., \& Muñoz, S. M. (2011). Revisiting validation theory: Theoretical foundations, applications, and extensions. Enrollment Management Journal, 2(1), 12-33.

Rocconi, L. M. (2010). The impact of learning communities on first year students' growth and development in college. Research in Higher Education, 52(2), 178193. doi: 10.1007/s11162-010-9190-3.

Rohrlick, J., Alvarado, D., Zaruba, K., \& Kallio, R. (1998). From the model minority to the invisible minority: Asian \& Pacific American students. In Thirty Eighth Annual Forum of the Association for Institutional Research (pp. 1-22). Minneapolis, Minnesota.

Research and Planning Group for California Community Colleges, (2013). Using Student Voices to Redefine Success: What Community College Students Say Institutions, Instructors and Others Can Do to Help Them Succeed. Retrieved from http://rpgroup.org/Our-Projects/Student-Support-Re-defined/Resources

Sam, A. L. A., \& Robinson, N. B. (1998). Pacific Islanders in higher education: Barriers to recruitment and retention. Pacific Educational Research Journal 9(1), 39-50. 
Shapiro, N. S. \& Levine, J. H. (1999). Creating learning communities: A practical guide for winning support, organizing change, and implementing programs. San Francisco: Jossey Bass.

Smith, L. T. (2013). Decolonizing methodologies: Research and indigenous peoples. Zed Books Ltd.

Smylie, M. (1996). From bureaucratic control to building human capital: The importance of teacher learning in education reform. Educational Researcher 25(9), 9-11.

Solorzano, D. G., \& Yosso, T. J. (2001). From racial stereotyping and deficit discourse toward a critical race theory in teacher education. Multicultural Education, 9(1), 2-8. Retrieved from http://search.proquest.com/docview/216501989/fulltextPDF/58539CD6A7FF43 $6 \mathrm{BPQ} / 1$ ?accountid $=34444$

Spickard, P. R., Rondilla, J. L., \& Wright, D. H. (Eds.). (2002). Pacific diaspora: Island peoples in the United States and across the Pacific. University of Hawaii Press.

Stebleton, M. J., \& Aleixo, M. B. (2015). Examining undocumented Latino/a student interactions with faculty and institutional agents. Journal of Hispanic Higher Education, 14(3), 256-273. doi:10.1177/1538192715574097

Takeuchi, D. and S. Hune. (2008). Growing presence, emerging voices: Pacific Islanderss and academic achievement in Washington. A report submitted to The Washington State Commission on Asian Pacific American Affairs. Seattle, WA: University of Washington

Taylor, C. M., \& Howard-Hamilton, M. F. (1995). Student involvement and racial identity attitudes among African American males. Journal of College Student Development, 36(4), 330-336. Retrieved from https://www.researchgate.net/publication/232524497.

Teranishi, R. T., Behringer, L. B., Grey, E. A.s \& Parker, T. L. (2009). Critical Race Theory and research on Asian Americans and Pacific Islanders in higher education. New Directions for Institutional Research, 142(Summer 2009), 5768. http://doi.org/10.1002/ir

Thaman, K.H. (1998). Equity in, and access to, what kind of education? Some issues for consideration in the pacific islands. Journal of Educational Studies, 20(2), 3-21. 
Thaman, K. H. (2001). Towards culturally inclusive teacher education with specific reference to Oceania. International Education Journal 2(5), 1-8.

Thaman, K.H. (2003). Decolonizing Pacific studies: Indigenous perspectives, knowledge and wisdom in higher education. The Contemporary Pacific 15(1), 117.

Tierney, W. G., (1999). Models of minority college-going and retention: Cultural integrity versus cultural suicide. Journal of Negro Education, 68(1), 80-91. Retrieved from http://www.jstor.org/stable/2668211

Tinto, V. (1975). Dropout from higher education: A theoretical synthesis of recent research. Review of Educational Research, 45(1), 89-125. Retrieved from http://www.jstor.org/stable/1170024

Tinto, V. (1988). Stages of student departure: Reflections on the longitudinal character of student leaving. The Journal of Higher Education, 59(4), 438-455.

Tinto, V. (1993). Leaving college: Rethinking the causes and cures of student attrition (2nd ed.). Chicago: University of Chicago Press.

Tinto, V. (1997). Classrooms as communities: Exploring the educational character of student persistence. The .Journal of Higher Education. 68(6), 599-623. Retrieved from http://0-www.jstor.org.opac.sfsu.edu/stable/2959965

Tinto, V. (2006). Research and practice of student retention: What next? Journal of College Student Retention 8(1), 1-19.

Tinto, V., \& Russo, P. (1994). Coordinated studies programs: Their effect on student involvement at a community college. Community College Review, 22(2), 16-25. doi: $10.1177 / 009155219402200203$

UCLA Asian American Studies Center (2006). Pacific Islanders lagging behind in higher educational attainment. Analytical Briefs on New Census Data. Retrieved from http://npien.com/images/PIEducationAttainBrief Nov14th.pdf.

United States Census Bureau (2017). Current Population Survey, Ánnual Social and Economic Supplement, 1992 through 2015. Retrieved from https://www.census.gov/programs-survevs/cps.html

United States Census Bureau (2010). The Native Hawaiian and Other Pacific Island Population. Retrieved from http://www.census.gov/prod/cen2010/briefs/c2010br-12.pdf. 
United States Census Bureau (2012). The population with a Bachelor's degree or higher by race and Hispanic origin: 2006-2010. Retrieved from http://www.census.gov/prod/2012pubs/acsbr10-19.pdf.

United States Census Bureau (2015). Projections of the size and composition of the U.S. population: 2014 to 2060. Retrieved from http://www.census.gov/content/dam/Census/library/publications/2015/demo/p25 -1143.pdf?

United States Census Bureau (2016). Quick Facts. Retrieved from https://www.census.gov/quickfacts/fact/table/CA/PST045216

Vaioleti, T. M. (2006). Talanoa Research Methodology: A Developing Position on Pacific Research. Paper presented at the Pacific Research : Education Symposium. Waikato Journal of Education, 12, 21-34.

Vakalahi, H. F. O. (2009). Pacific Islander American students: Caught between a rock and a hard place? Children and Youth Services Review, 31(12), 1258-1263. http://doi.org/10.1016/i.childyouth.2009.05.011

Vaught, S. E. (2012). "They might as well be Black": The racialization of Sa'moan high school students. International Journal of Qualitative Studies in Education, 25(5), 557-582. http://doi.org/10.1080/09518398.2010.538746

Walter, M., \& Andersen, C. (2013). Indigenous statistics: A quantitative research methodology. Left Coast Press.

Watson-Gegeo, K. \& Gegeo, D. (1992). Schooling, knowledge, and power: Social transformation in the Solomon Islands. Anthropology \& Education Quarterly 23(1), 10-29.

Webber, K. L., Krylow, R. B., \& Zhang, Q. (2013). Does involvement really matter? Indicators of college student success and satisfaction. Journal of College Student Development, 54(6), 591-611. http://doi.org/10.1353/csd.2013.0090

Weiss, M. J., Visher, M. G., Weissman, E., \& Wathington, H. D. (2015). The Impact of Learning Communities for Students in Developmental Education: A Synthesis of Findings from Randomized Trials at Six Community Colleges. Educational Evaluation and Policy Analysis, 37(4), 520-541. http://doi.org/10.3102/0162373714563307

Wheelan, C. (2013). Naked statistics: Stripping the dread from the data. New York, NY: W.W. Norton \& Company. 
Wolf-Wendel, L., Ward, K., Kinzie, J. (2009). A tangled web of terms: The overlap and unique contribution of involvement, engagement, and integration to understanding college student success. Journal of College Student Development 50(4), 407-428.

Xiong, S., Allen, C., \& Wood, J. L. (2016). The role of community college counselors as validating agents on men of color student success. Community College Journal of Research and Practice, 40(6), 558-561. http://doi.org/10.1080/10668926.2015.1096222

Yeh, T.L. (2004). Issues of college persistence between Asian and Asian Pacific American students. Journal of College Student Retention, 6(1), 81-96.

Yeh, C.J., Borrero, N.E., Tito, P., \& Petaia, L.S. (2014). Intergenerational stories and the "othering" of Samoan youth in schools. Urban Review, 46(2), 147-168.

Yosso, T. J. (2005). Whose culture has capital? A critical race theory discussion of community cultural wealth. Race Ethnicity and Education, 8(1), 69-91. http://doi.org/10.1080/1361332052000341006

Zhao, C. M., Carini, R. M., \& Kuh, G. D. (2005). Searching for the peach blossom Shangri-La: Student engagement of men and women SMET majors. The Review of Higher Education, 28(4), 503-525.

Zhao, C. M., \& Kuh, G. D. (2004). Adding value: Learning communities and student engagement. Research in Higher Education, 45(2), 115-138. 


\section{Appendix 1}

\section{Questionnaire}

The following questionnaire will take approximately 20 minutes to complete. You are not required to answer any questions with which you are uncomfortable.

Select the answer which best fits

\begin{tabular}{|l|c|c|c|c|c|c|c|}
\hline & $\begin{array}{l}\text { Very } \\
\text { strongly }\end{array}$ & disagree & & Neutral & & Very \\
strongly \\
agree
\end{tabular}




\begin{tabular}{|l|l|l|l|l|l|l|l|}
\hline $\begin{array}{l}\text { At least one } \\
\text { instructor has talked } \\
\text { with me about my } \\
\text { personal goals at this } \\
\text { college }\end{array}$ & 1 & 2 & 3 & 4 & 5 & 6 & 7 \\
\hline $\begin{array}{l}\text { My instructors } \\
\text { understand that } \\
\text { students come from } \\
\text { different } \\
\text { backgrounds }\end{array}$ & 1 & 2 & 3 & 4 & 5 & 6 & 7 \\
\hline $\begin{array}{l}\text { I have had at least } \\
\text { one instructor at this } \\
\text { college who helped } \\
\text { me believe in myself }\end{array}$ & 1 & 2 & 3 & 4 & 5 & 6 & 7 \\
\hline $\begin{array}{l}\text { College staff other } \\
\text { than faculty } \\
\text { encourage me to get } \\
\text { involved in campus } \\
\text { activities }\end{array}$ & 1 & 2 & 3 & 4 & 5 & 6 & 7 \\
\hline $\begin{array}{l}\text { My instructors are } \\
\text { willing to take as } \\
\text { long as needed to } \\
\text { help me understand } \\
\text { the class material }\end{array}$ & 1 & 2 & 3 & 4 & 5 & 6 & 7 \\
\hline $\begin{array}{l}\text { I'm certain I can } \\
\text { master the skills } \\
\text { taught at this college }\end{array}$ & 1 & 2 & 3 & 4 & 5 & 6 & 7 \\
\hline $\begin{array}{l}\text { I have had } \\
\text { opportunities to talk } \\
\text { about career plans } \\
\text { with an adviser or } \\
\text { staff member }\end{array}$ & 1 & 2 & 3 & 4 & 5 & 6 & 7 \\
\hline $\begin{array}{l}\text { At least one staff } \\
\text { member has taken an } \\
\text { interest in my } \\
\text { development }\end{array}$ & 1 & 2 & 3 & 4 & 5 & 6 & 7 \\
\hline
\end{tabular}




\begin{tabular}{|l|l|l|l|l|l|l|l|}
\hline $\begin{array}{l}\text { It is important to see } \\
\text { college faculty and } \\
\text { staff that reflect my } \\
\text { ethnic and cultural } \\
\text { identity }\end{array}$ & 1 & 2 & 3 & 4 & 5 & 6 & 7 \\
\hline $\begin{array}{l}\text { I have had one or } \\
\text { more individuals at } \\
\text { this college whom I } \\
\text { thought of as a } \\
\text { mentor }\end{array}$ & 1 & 2 & 3 & 4 & 5 & 6 & 7 \\
\hline $\begin{array}{l}\text { My instructors are } \\
\text { easily accessible } \\
\text { outside of their } \\
\text { classrooms }\end{array}$ & 1 & 2 & 3 & 4 & 5 & 6 & 7 \\
\hline $\begin{array}{l}\text { I see myself as part } \\
\text { of the campus } \\
\text { community }\end{array}$ & 1 & 2 & 3 & 4 & 5 & 6 & 7 \\
\hline $\begin{array}{l}\text { My achievements } \\
\text { are recognized by } \\
\text { someone other than } \\
\text { faculty }\end{array}$ & 1 & 2 & 3 & 4 & 5 & 6 & 7 \\
\hline $\begin{array}{l}\text { My instructors seem } \\
\text { to genuinely care } \\
\text { how I am doing }\end{array}$ & 1 & 2 & 3 & 4 & 5 & 6 & 7 \\
\hline $\begin{array}{l}\text { My instructors } \\
\text { generally remember } \\
\text { my name }\end{array}$ & 1 & 2 & 3 & 4 & 5 & 6 & 7 \\
\hline $\begin{array}{l}\text { Even if the work is } \\
\text { my classes is hard I } \\
\text { can learn it }\end{array}$ & 1 & 2 & 3 & 4 & 5 & 6 & 7 \\
\hline $\begin{array}{l}\text { I am encouraged to } \\
\text { share life } \\
\text { experiences when } \\
\text { they relate to the } \\
\text { class material }\end{array}$ & 1 & 2 & 3 & 4 & 5 & 6 & 7 \\
\hline $\begin{array}{l}\text { My instructors } \\
\text { provide lots of } \\
\text { written feedback on } \\
\text { the assignments I } \\
\text { turn in }\end{array}$ & 1 & 2 & 3 & 4 & 5 & 6 & 7 \\
\hline
\end{tabular}




\begin{tabular}{|l|l|l|l|l|l|l|l|}
\hline $\begin{array}{l}\text { I feel that I am a } \\
\text { member of the } \\
\text { campus community }\end{array}$ & 1 & 2 & 3 & 4 & 5 & 6 & 7 \\
\hline $\begin{array}{l}\text { My instructors try to } \\
\text { make their classes } \\
\text { interesting }\end{array}$ & 1 & 2 & 3 & 4 & 5 & 6 & 7 \\
\hline $\begin{array}{l}\text { Women are } \\
\text { encouraged to } \\
\text { contribute to the } \\
\text { class discussion }\end{array}$ & 1 & 2 & 3 & 4 & 5 & 6 & 7 \\
\hline $\begin{array}{l}\text { My instructors are } \\
\text { willing to give me } \\
\text { individual help when } \\
\text { needed }\end{array}$ & 1 & 2 & 3 & 4 & 5 & 6 & 7 \\
\hline $\begin{array}{l}\text { If I have enough } \\
\text { time I can do a good } \\
\text { job on all of my } \\
\text { coursework }\end{array}$ & 1 & 2 & 3 & 4 & 5 & 6 & 7 \\
\hline $\begin{array}{l}\text { I can do even the } \\
\text { hardest coursework } \\
\text { if I try }\end{array}$ & 1 & 2 & 3 & 4 & 5 & 6 & 7 \\
\hline $\begin{array}{l}\text { Most instructors are } \\
\text { interested in what I } \\
\text { have to offer in class }\end{array}$ & 1 & 2 & 3 & 4 & 5 & 6 & 7 \\
\hline $\begin{array}{l}\text { I interact with my } \\
\text { instructors outside of } \\
\text { class }\end{array}$ & 1 & 2 & 3 & 4 & 5 & 6 & 7 \\
\hline $\begin{array}{l}\text { I am encouraged by } \\
\text { my instructors to } \\
\text { openly share my } \\
\text { views in class }\end{array}$ & 1 & 2 & 3 & 4 & 5 & 6 & 7 \\
\hline $\begin{array}{l}\text { I feel a sense of } \\
\text { belonging to the } \\
\text { campus community }\end{array}$ & 1 & 2 & 3 & 4 & 5 & 6 & 7 \\
\hline $\begin{array}{l}\text { I'm certain I can } \\
\text { figure out how to do } \\
\text { the most difficult } \\
\text { coursework }\end{array}$ & 1 & 2 & 3 & 4 & 5 & 6 & 7 \\
\hline $\begin{array}{l}\text { My instructors know } \\
\text { who I am }\end{array}$ & 1 & 2 & 3 & 4 & 5 & 6 & 7 \\
\hline
\end{tabular}




\begin{tabular}{|l|l|l|l|l|l|l|l|}
\hline $\begin{array}{l}\text { I feel like my } \\
\text { personal and family } \\
\text { history is valued in } \\
\text { class }\end{array}$ & 1 & 2 & 3 & 4 & 5 & 6 & 7 \\
\hline $\begin{array}{l}\text { I can generally } \\
\text { express my honest } \\
\text { opinions in my } \\
\text { classes }\end{array}$ & 1 & 2 & 3 & 4 & 5 & 6 & 7 \\
\hline
\end{tabular}




\section{Appendix 2}

Indices Sub-scale Items

\begin{tabular}{|l|c|c|c|}
\hline \multicolumn{1}{|c|}{ Survey Item } & \multicolumn{3}{|c|}{ Index Measurement } \\
\cline { 2 - 4 } & Faculty Validation & $\begin{array}{c}\text { Validation by } \\
\text { Others }\end{array}$ & $\begin{array}{c}\text { Competent } \\
\text { Membership }\end{array}$ \\
\hline $\begin{array}{l}\text { I feel accepted as a } \\
\text { person by my } \\
\text { instructors }\end{array}$ & $\mathrm{X}$ & \\
\hline $\begin{array}{l}\text { My instructors } \\
\text { show that they } \\
\text { believe in my } \\
\text { ability to do the } \\
\text { class work }\end{array}$ & $\mathrm{X}$ & & \\
\hline $\begin{array}{l}\text { I can do most of } \\
\text { my school work if I } \\
\text { don't give up }\end{array}$ & & & \\
\hline $\begin{array}{l}\text { I feel accepted as a } \\
\text { capable student by } \\
\text { my instructors }\end{array}$ & $\mathrm{X}$ & & \\
\hline $\begin{array}{l}\text { My instructors } \\
\text { make me feel as } \\
\text { though I brig } \\
\text { valuable ideas to } \\
\text { class }\end{array}$ & & & \\
\hline $\begin{array}{l}\text { It seems like my } \\
\text { instructors really } \\
\text { care about whether } \\
\text { I am learning }\end{array}$ & $\mathrm{X}$ & $\mathrm{X}$ \\
\hline $\begin{array}{l}\text { I feel as though I } \\
\text { am treated equally } \\
\text { to other students }\end{array}$ & $\mathrm{X}$ & & \\
\hline $\begin{array}{l}\text { At least one } \\
\text { instructor has } \\
\text { talked with me } \\
\text { about my personal } \\
\text { goals at this college }\end{array}$ & & & \\
\hline
\end{tabular}




\begin{tabular}{|l|l|l|l|}
\hline $\begin{array}{l}\text { My instructors } \\
\text { understand that } \\
\text { students come from } \\
\text { different } \\
\text { backgrounds }\end{array}$ & $\quad \mathrm{X}$ & & \\
\hline $\begin{array}{l}\text { I have had at least } \\
\text { one instructor at } \\
\text { this college who } \\
\text { helped me believe } \\
\text { in myself }\end{array}$ & $\quad \mathrm{X}$ & & \\
\hline $\begin{array}{l}\text { College staff other } \\
\text { than faculty } \\
\text { encourage me to } \\
\text { get involved in } \\
\text { campus activities }\end{array}$ & & & \\
\hline $\begin{array}{l}\text { My instructors are } \\
\text { willing to take as } \\
\text { long as needed to } \\
\text { help me understand } \\
\text { the class material }\end{array}$ & & & \\
\hline $\begin{array}{l}\text { I'm certain I can } \\
\text { master the skills } \\
\text { taught at this } \\
\text { college }\end{array}$ & & & \\
\hline $\begin{array}{l}\text { I have had } \\
\text { opportunities to } \\
\text { talk about career } \\
\text { plans with an } \\
\text { adviser or staff } \\
\text { member }\end{array}$ & & & \\
\hline $\begin{array}{l}\text { At least one staff } \\
\text { member has taken } \\
\text { an interest in my } \\
\text { development }\end{array}$ & & & \\
\hline $\begin{array}{l}\text { It is important to } \\
\text { see college faculty } \\
\text { and staff that } \\
\text { reflect my ethnic } \\
\text { and cultural } \\
\text { identity }\end{array}$ & & & \\
\hline
\end{tabular}




\begin{tabular}{|l|l|l|l|}
\hline $\begin{array}{l}\text { I have had one or } \\
\text { more individuals at } \\
\text { this college whom I } \\
\text { thought of as a } \\
\text { mentor }\end{array}$ & & & \\
\hline $\begin{array}{l}\text { My instructors are } \\
\text { easily accessible } \\
\text { outside of their } \\
\text { classrooms }\end{array}$ & $\quad \mathrm{X}$ & \\
\hline $\begin{array}{l}\text { I see myself as part } \\
\text { of the campus } \\
\text { community }\end{array}$ & & & \\
\hline $\begin{array}{l}\text { My achievements } \\
\text { are recognized by } \\
\text { someone other than } \\
\text { faculty }\end{array}$ & & & \\
\hline $\begin{array}{l}\text { My instructors } \\
\text { seem to genuinely } \\
\text { care how I am } \\
\text { doing }\end{array}$ & & $\mathrm{X}$ & \\
\hline $\begin{array}{l}\text { My instructors } \\
\text { generally } \\
\text { remember my } \\
\text { name }\end{array}$ & & & \\
\hline $\begin{array}{l}\text { Even if the work is } \\
\text { my classes is hard I } \\
\text { can learn it }\end{array}$ & & & \\
\hline $\begin{array}{l}\text { I am encouraged to } \\
\text { share life } \\
\text { experiences when } \\
\text { they relate to the } \\
\text { class material }\end{array}$ & & & \\
\hline $\begin{array}{l}\text { My instructors } \\
\text { provide lots of } \\
\text { written feedback } \\
\text { on the assignments } \\
\text { I turn in }\end{array}$ & & & \\
\hline $\begin{array}{l}\text { I feel that I am a } \\
\text { member of the } \\
\text { campus community }\end{array}$ & & & \\
\hline & & & \\
\hline
\end{tabular}




\begin{tabular}{|l|l|l|l|}
\hline $\begin{array}{l}\text { My instructors try } \\
\text { to make their } \\
\text { classes interesting }\end{array}$ & X & & \\
\hline $\begin{array}{l}\text { Women are } \\
\text { encouraged to } \\
\text { contribute to the } \\
\text { class discussion }\end{array}$ & $\mathrm{X}$ & & \\
\hline $\begin{array}{l}\text { My instructors are } \\
\text { willing to give me } \\
\text { individual help } \\
\text { when needed }\end{array}$ & $\quad \mathrm{X}$ & & \\
\hline $\begin{array}{l}\text { If I have enough } \\
\text { time I can do a } \\
\text { good job on all of } \\
\text { my coursework }\end{array}$ & & & \\
\hline $\begin{array}{l}\text { I can do even the } \\
\text { hardest coursework } \\
\text { if I try }\end{array}$ & & & \\
\hline $\begin{array}{l}\text { Most instructors } \\
\text { are interested in } \\
\text { what I have to offer } \\
\text { in class }\end{array}$ & & $\mathrm{X}$ \\
\hline $\begin{array}{l}\text { I interact with my } \\
\text { instructors outside } \\
\text { of class }\end{array}$ & & $\mathrm{X}$ & $\mathrm{X}$ \\
\hline $\begin{array}{l}\text { I am encouraged by } \\
\text { my instructors to } \\
\text { openly share my } \\
\text { views in class }\end{array}$ & & $\mathrm{X}$ & \\
\hline $\begin{array}{l}\text { I feel a sense of } \\
\text { belonging to the } \\
\text { campus community }\end{array}$ & & & \\
\hline $\begin{array}{l}\text { I'm certain I can } \\
\text { figure out how to } \\
\text { do the most } \\
\text { difficult } \\
\text { coursework }\end{array}$ & & & \\
\hline $\begin{array}{l}\text { My instructors } \\
\text { know who I am }\end{array}$ & & & \\
\hline
\end{tabular}




\begin{tabular}{|l|l|l|l|}
\hline $\begin{array}{l}\text { I feel like my } \\
\text { personal and } \\
\text { family history is } \\
\text { valued in class }\end{array}$ & $\mathrm{X}$ & & \\
\hline $\begin{array}{l}\text { I can generally } \\
\text { express my honest } \\
\text { opinions in my } \\
\text { classes }\end{array}$ & $\mathrm{X}$ & & \\
\hline
\end{tabular}

